\title{
Multifunctional optrode for opsin delivery, optical stimulation, and electrophysiological recordings in freely moving rats
}

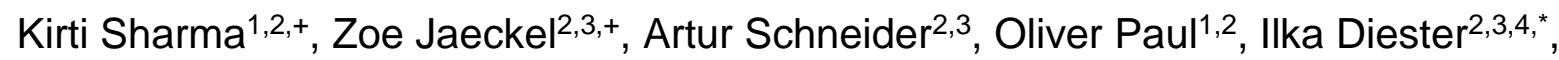
Patrick Ruther ${ }^{1,2,{ }^{*}}$

${ }^{1}$ Department of Microsystems Engineering (IMTEK), University of Freiburg, Germany

2 Cluster of Excellence BrainLinks-BrainTools, University of Freiburg, Germany

${ }^{3}$ Faculty of Biology, Optophysiology, University of Freiburg, Germany

${ }^{4}$ Bernstein Center, University of Freiburg, Germany

+ Equal contribution

* Corresponding authors
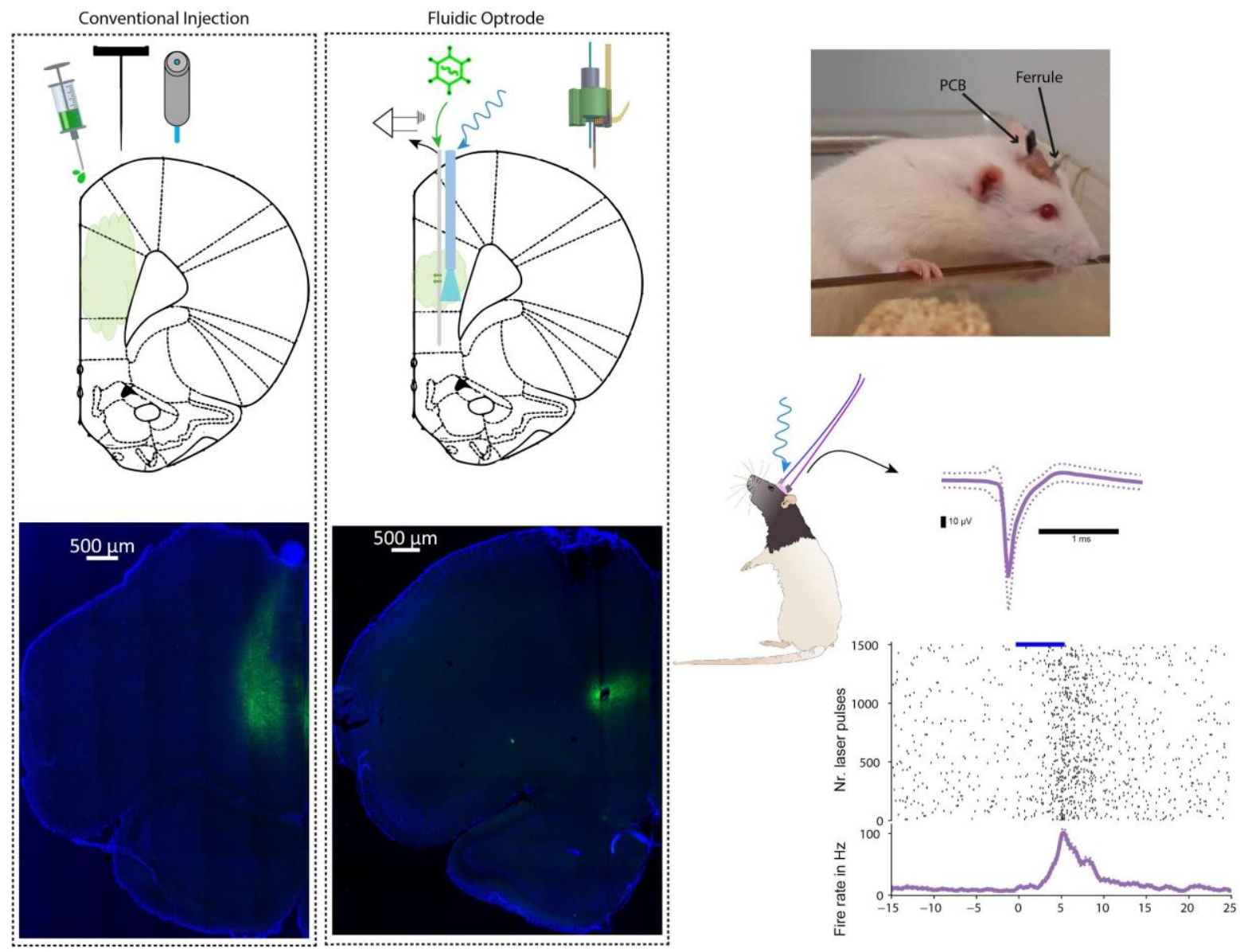

Graphical abstract 


\begin{abstract}
Objective. Optogenetics involves delivery of light-sensitive opsins to the target brain region, as well as introduction of optical and electrical devices to manipulate and record neural activity, respectively, from the targeted neural population. Combining these functionalities in a single implantable device is of great importance for a precise investigation of neural networks while minimizing tissue damage. Approach. We report on the development, characterization, and in vivo validation of a multifunctional optrode that combines a silicon-based neural probe with an integrated microfluidic channel, and an optical glass fiber in a compact assembly. The silicon probe comprises an $11-\mu \mathrm{m}$-wide fluidic channel and 32 recording electrodes (diameter $30 \mu \mathrm{m}$ ) on a tapered probe shank with a length, thickness, and maximum width of $7.5 \mathrm{~mm}, 50$ $\mu \mathrm{m}$, and $150 \mu \mathrm{m}$, respectively. The size and position of fluidic channels, electrodes, and optical fiber can be precisely tuned according to the in vivo application. Main results. With a total system weight of $0.97 \mathrm{~g}$, our multifunctional optrode is suitable for chronic in vivo experiments requiring simultaneous drug delivery, optical stimulation, and neural recording. We demonstrate the utility of our device in optogenetics by injecting a viral vector carrying a ChR2construct in the prefrontal cortex and subsequent photostimulation of the transfected neurons while recording neural activity from both the target and adjacent regions in a freely moving rat. Additionally, we demonstrate a pharmacological application of our device by injecting GABA antagonist bicuculline in an anesthetized rat brain and simultaneously recording the electrophysiological response. Significance. Our triple-modality device enables a single-step optogenetic surgery. In comparison to conventional multi-step surgeries, our approach achieves higher spatial specificity while minimizing tissue damage.
\end{abstract}

Keywords: drug delivery, viral delivery, microfluidic neural probe, buried channels, multifunctional probe, optrode, chronic implantation, in vivo optogenetics, optogenetics in rats

\title{
1. Introduction
}

One of the main questions of neuroscientific research is what neural activity underlies a specific behavior or function. While research has advanced with techniques such as the correlation of neurophysiological recordings with behavior, neuromodulation enables a closer observation of causal or necessary neural functions for a specific behavior. Neuromodulation with high spatiotemporal resolution is vital to efficiently investigate neural networks. What was once accomplished with high-artifact electrical stimulation is now often investigated via a more specific, less artifact-prone optical neuromodulation termed optogenetics (Boyden et al., 2005).

This technique is a combination of genetic and optical methods which allows to reversibly excitate or inhibit activity in specific cell populations in systems as complex as freely moving animals (Deisseroth, 2011). This involves integration of light-sensitive membrane proteins, i.e., opsins, into neurons via genetic manipulation. Opsins react to specific wavelengths of light, allowing for a manipulation of neuronal activity. Some opsins are depolarizing, such as channelrhodopsin-2 (ChR2), a cation channel that induces action potentials in response to blue light (Boyden et al., 2005; Nagel et al., 2003). Others are hyperpolarizing, such as the chloride pump halorhodopsin (Zhang et al., 2007). Integration of opsins into neurons has enabled optic neuromodulation at high spatiotemporal resolution (Boyden et al., 2005; Han \& 
Boyden, 2007). This field encompasses diverse strategies to target specific cell populations or projections, making it a powerful toolbox for dissecting neural circuits (De La Crompe et al., 2020). The genetic introduction of opsins is achieved via viral vectors with cell-type-specific promoters, transgenic animals, or a combination of both. This provides specific targeting of defined cell-types or projection-specific neural populations. The desired modulation target can then be further spatially restricted by the area of light application. The type of opsin integrated and light pattern applied can also be modified to provide high temporal control over the neuromodulation (Li et al., 2005). In combination, these adaptable features offer the benefit of high spatiotemporal neural inhibition or excitation of specific cell populations or projections, proving advantageous over electrical stimulation, which can only unspecifically activate all cells in the area near the stimulation site with comparably low spatiotemporal resolution.

While optogenetics currently is the prominent method of neuromodulation, electrophysiology is still the method of choice for recording neural activity with the highest temporal resolution. As opposed to electrical stimulation, optogenetic modulation causes little interference with electrophysiological recordings. Neuroengineering has made significant progress in applying these two methods for simultaneous neuromodulation and recording, for example, via optrodes (H. Kim et al., 2020; K. Kim et al., 2020; Royer et al., 2010). Optrodes, which combine the functions of light application and electrophysiological recording, have become increasingly relevant for optogenetic experiments in order to optogenetically alter a specific cell population while recording its neuronal activity.

Despite its undisputed merits, the technique of optogenetics leaves room for further refinements. For example, one way of integrating opsins into an in vivo model relies on viral injection into a brain area. This is typically achieved with stereotaxic surgery using a nanosyringe or micropipette. After viral injection, the syringe is retreated from the brain, whereupon another device must be inserted in order to provide a light source for accomplishing the desired optogenetic manipulation. This can pose problems, such as backflow of the virus when retreating the injection tool (Fig. S1), or damage to the brain tissue due to repeated device insertions in the same area. To avoid these issues and allow for a single-insertion implantation surgery, it is of interest to combine fluidic, optical and electrical recording functionalities in a single device. Recently such triple-modality probes have come into focus for more efficient interrogation of neural circuitry (Canales et al., 2015; Park et al., 2017; Shin et al., 2019, 2021). Park et al. 2017 and Canales et al. 2015 integrated these modalities in flexible polymer fibers fabricated using a fiber drawing process. They made large strides with long-term, complex experimental testing of their devices in mice with simultaneous optical stimulation, neural recording, and viral (Park et al. 2017) or drug delivery (Canales et al. 2015). Although these multifunctional fiber probes come with a miniature footprint, the technology suffers from a few design limitations. The position of electrodes, fluidic outlets and optical ports is limited to the tip of the fibers, and a manual back-end connectorization of individual electrodes limits the expansion of the number of recording sites. Microelectromechanical systems (MEMS) technology offers higher design flexibility while maintaining a small footprint, as shown in silicon-based multifunctional probes by Shin et al. 2019. They monolithically integrated an optical waveguide, fluidic channel, and electrodes in a planar multi-shank array. Shin et al. 2019 demonstrated the functionality of their probe through simultaneous drug delivery, optical stimulation and neural recording in transgenic mice through acute experiments, but did not implement the probe for viral delivery or electrophysiology in freely moving animals. In this work, we present a multifunctional optrode which combines a MEMS- 
fabricated microfluidic probe with an optical fiber, and implement it for viral delivery, and subsequent optical stimulation and neural recording in a chronically implanted freely moving rat.

MEMS-based neural probes can be equipped with microfluidic channels using three different fabrication approaches, i.e., surface micromachining, substrate bonding, and bulk micromachining (Sim et al., 2017). Surface micromachining results in channels on top of the device substrate. Typically, the fabrication process starts with patterning a sacrificial material which is subsequently covered by a channel material such as silicon nitride (Retterer et al., 2004) or parylene C (Neeves et al., 2006), followed by the selective removal of the former sacrificial material to realize microchannels. Particularly in the case of long and narrow channels, the channel formation is restricted by the diffusion-limited removal of the sacrificial material from the channel inlet and outlet ports. As a solution, channels can be equipped with etch holes along their length that facilitate the diffusion-driven etching of the sacrificial material (Retterer et al., 2004). However, these etch holes need to be subsequently sealed using a vapor phase deposition process. In the case of the wafer bonding approach, recessed channels are created in one substrate wafer; they are subsequently sealed from the top side by bonding a second material to the substrate. Silicon (Seidl et al., 2010; Spieth et al., 2011), glass (Shin et al., 2019), parylene (Ziegler et al., 2006) and polyimide (Moser et al., 2012) have been applied for channel sealing. Up to this point, the channel dimensions are not constrained by any processing step. However, following the critical wafer bonding, an additional thinning process might be required (Seidl et al., 2010; Shin et al., 2019; Spieth et al., 2011). Lastly, bulk micromachining is capable of generating buried microfluidic channels in silicon ( $\mathrm{Si}$ ) wafers by applying Si etching and subsequent sealing processes (Groenesteijn et al., 2017). Channels are formed by either wet (J. Chen et al., 1997; Cheung et al., 2003) or dry (P.-J. Chen et al., 2006; Dijkstra et al., 2007; Pongrácz et al., 2013) etching of Si through small openings in a micro-patterned masking layer. The channel size can be controlled by adjusting the etching time. The small openings in the masking layer are subsequently sealed using chemical vapor deposition (CVD) processes. In this work, we used bulk micromachining of $\mathrm{Si}$ using continuous-flow (cf) xenon difluoride $\left(\mathrm{XeF}_{2}\right)$ etching to produce buried channels with semi-circular cross-sections in the $\mathrm{Si}$ substrate. $\mathrm{XeF}_{2}$ etching of $\mathrm{Si}$ is an isotropic, gas-phase, plasma-free process performed at room-temperature; it offers a very high etch selectivity to materials commonly used in MEMS engineering such as silicon oxide (SiOx), silicon nitride (SiNy), photoresist (PR), and aluminum (Williams et al., 2003). We have characterized cf-XeF 2 etching to realize microfluidic channels in detail in our previous work (Sharma et al., 2019).

In this work, we developed a microfluidic neural probe with a buried fluidic microchannel and a high-density linear array of recording electrodes at application-specific locations along the probe length. Furthermore, we created the multifunctional optrode by assembling the microfluidic probe close to an optical fiber in a small, 3D-printed unit. The optical fiber interfaced with an external laser offers a wide range of stimulation wavelengths and optical powers. The microfluidic probe and the fiber tip are aligned in such a way that specific fluidic injection and light illumination are allowed in either the prelimbic cortex (PL) or infralimbic cortex (IL), while it is possible to record from both areas. These areas are adjacent yet separate subareas of the medial prefrontal cortex, which are also heavily interconnected (Mukherjee \& Caroni, 2018). The reciprocal connectivity between PL and IL has been shown to affect ILmediated learning (Mukherjee \& Caroni, 2018). It has further been shown that PL and IL play opposing roles in various behaviors such as goal-directed learning, fear learning, and learning 
vs applying rules (Fenton et al., 2014; Hardung et al., 2017; Mukherjee \& Caroni, 2018). Because of their opposing functions, it is important to specifically target one area without externally influencing the other; only then can clear behavioral results be acquired. This can prove difficult, since injections into small areas such as IL can also end up transducing neighboring areas, such as the PL. This can occur due to general viral spread, but also from backflow of the virus when retreating the injection needle from the brain, as demonstrated in Fig. S1. Considering the interconnectivity, proximity, and context-dependent functionality of these two areas, it is of interest to target one area while recording in both.

With fluid delivery, light delivery, and recording electrodes combined in a single device, our multifunctional optrode enables a single-insertion implantation surgery for optogenetic application with neurophysiological recording. We demonstrate, to our knowledge, the first utility of a device for injecting the viral solution, chronic implantation for several weeks to allow viral expression, and photostimulating neurons near the injection site while recording neural activity both at and adjacent to the injection area in an awake, freely moving rat. Additionally, this novel tool can also be used for delivery of other pharmacological agents in the brain. In another experiment, therefore, we modulated neural activity in an anesthetized rat through bicuculline injections and simultaneously recorded the electrophysiological response.

\section{Materials and Methods}

\subsection{Device design}

The multifunctional optrode comprises a microfluidic neural probe combined with a ferruleterminated optical glass fiber. The probe and the glass fiber are aligned in parallel and close to each other on a 3D-printed unit (Fig. 1(A)). A schematic of the fluidic probe is depicted in Fig. 1(B). It contains a fluidic channel and recording electrodes along its slender probe shank. The shank is attached to a broader probe base that mediates the fluidic and electrical interconnections via inlet ports and bonding pads, respectively. The protruding design of the fluidic inlet port facilitates the in-plane connection of flexible tubings. The electrodes are connected to the external recording equipment using a highly flexible polyimide (PI) ribbon cable flip-chip bonded to the contact pads (Kisban et al., 2009). The cross-sections of the probe shank along lines A-A' and B-B', as illustrated in Fig. 1(B), are shown in Fig. 1(C(viii)). As indicated, the fluidic channel is located beneath the probe surface directly under the electrodes and interconnection lines. The fluidic outlet of the channel opens to one side of the probe shank.

For the application chosen in this study, we designed Si-based fluidic probes comprising a single $11-\mu \mathrm{m}$-wide fluidic channel and 32 recording electrodes (diameter $30 \mu \mathrm{m}$ ) on a tapered probe shank with a length, thickness, and maximum width of $7.5 \mathrm{~mm}, 50 \mu \mathrm{m}$, and $150 \mu \mathrm{m}$, respectively. The electrodes are arranged at a pitch of $60 \mu \mathrm{m}$ towards the tip (electrodes 1-16) and a pitch of $85 \mu \mathrm{m}$ towards the upper part of the shank (electrodes 17-32). This was custom designed so that we have 16 recording electrodes in each area, i.e., the IL and the PL. Each probe carries a single fluidic channel that ends in two closely spaced outlet ports. There are two design variants of the fluidic probe, which vary in the position of the fluidic outlet. The IL 

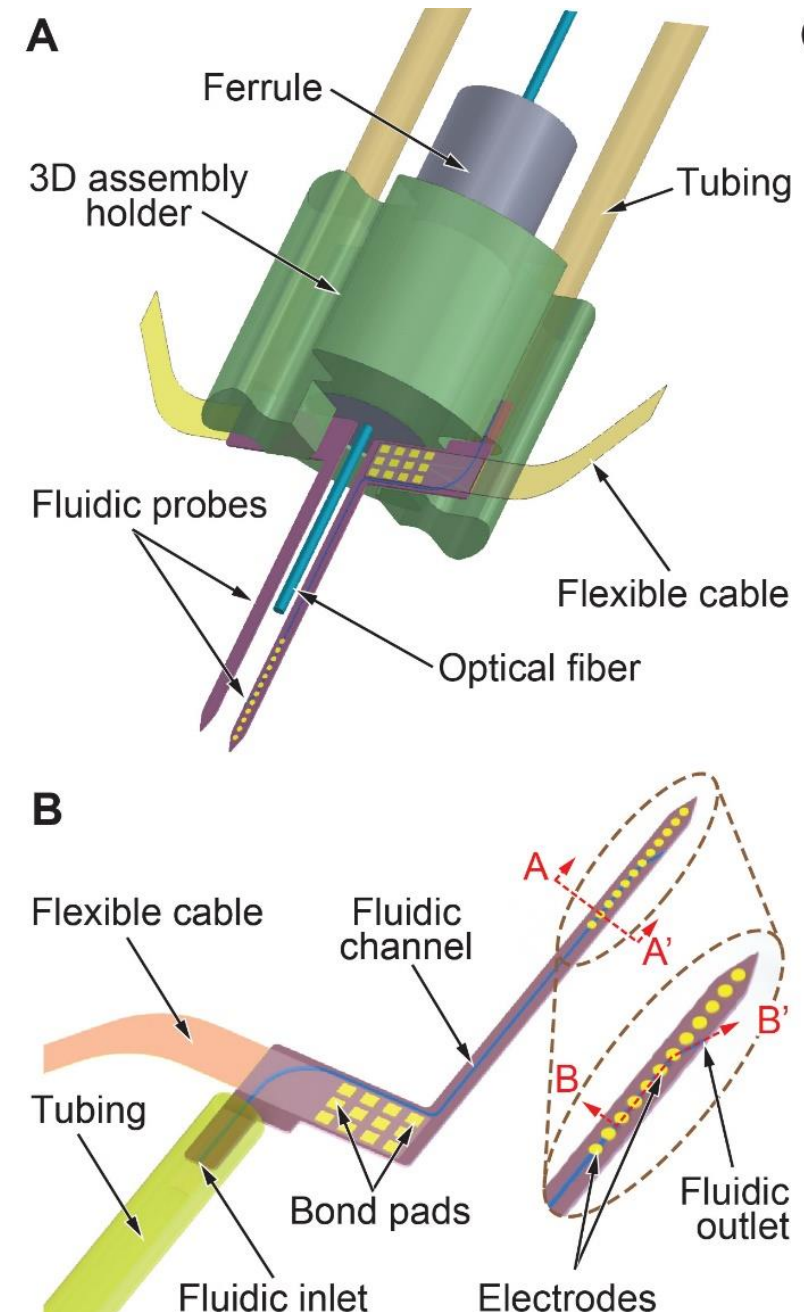

C (i) PECVD and patterning of mask layer

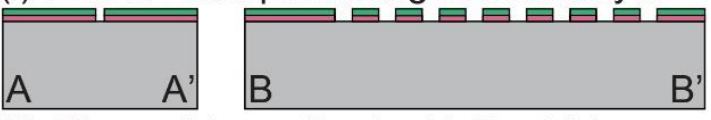

(ii) Channel formation by $\mathrm{XeF}_{2}$ etching

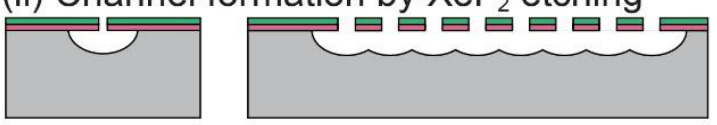

(iii) Sealing etch openings by PECVD

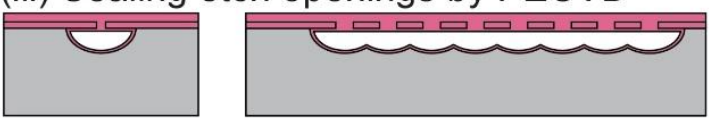

(iv) Metal evaporation and lift-off

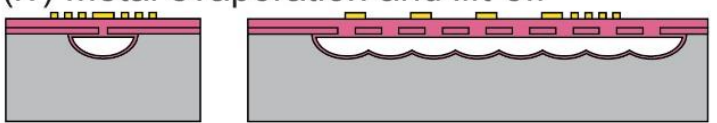

(v) Passivation and via etch

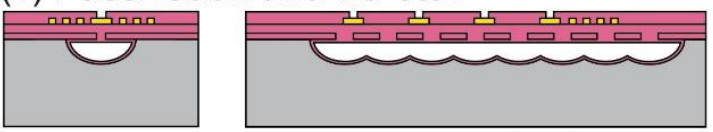

(vi) Electrode sputtering and lift-off

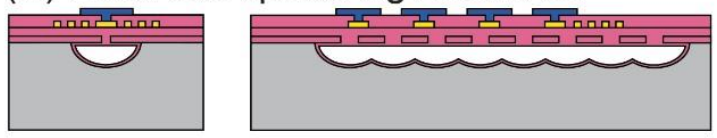

(vii) Patterning of probe shape

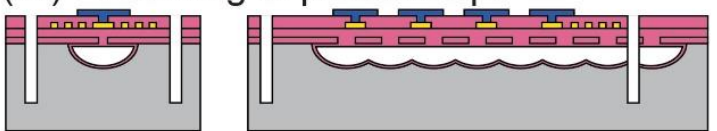

(viii) Probe thinning by grinding
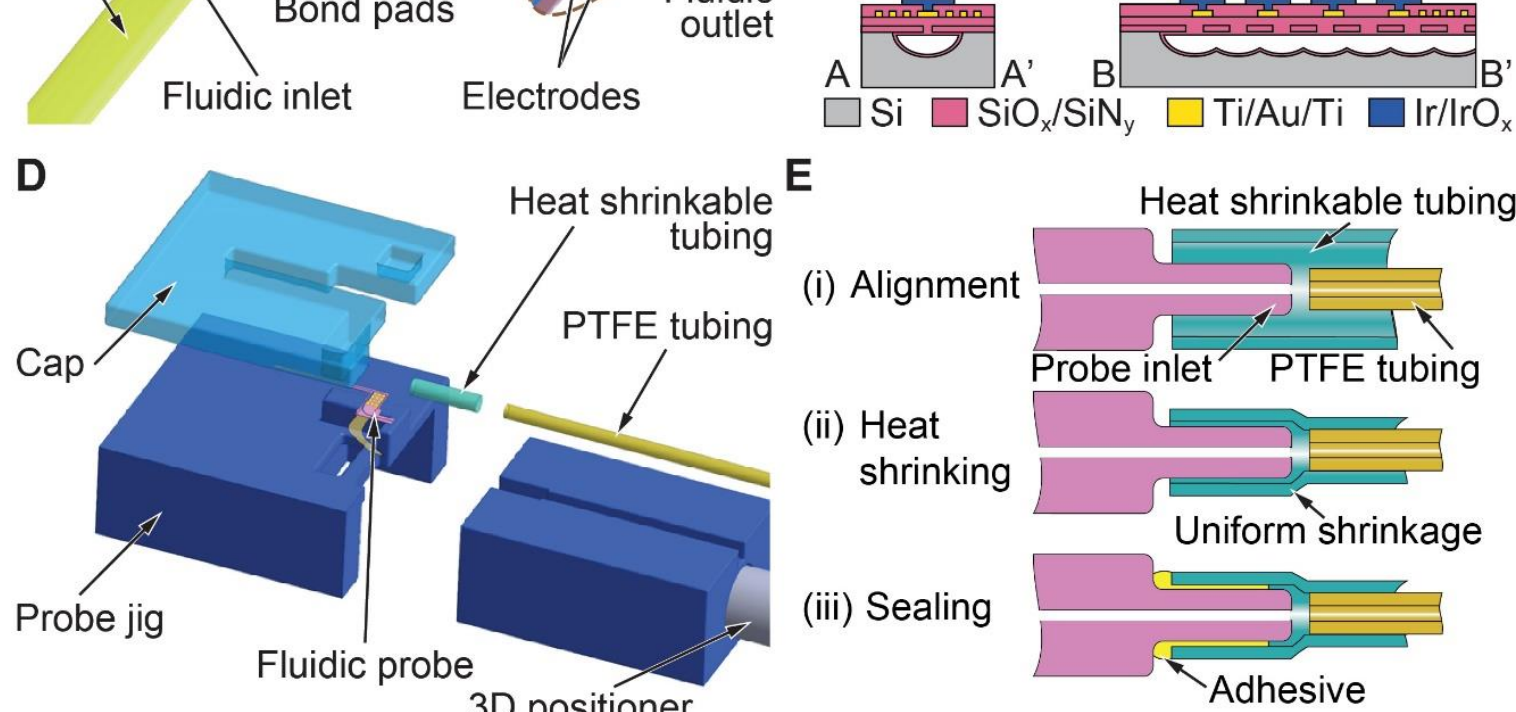

E

(i) Alignment

Heat shrinkable tubing

(ii) Heat

shrinking

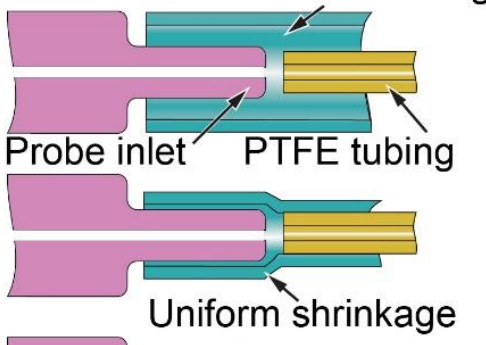

(iii) Sealing

3D positioner

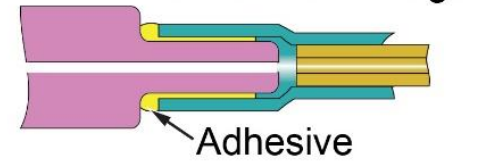

Figure 1: (A) Schematic of multifunctional optrode based on a microfluidic neural probe and an optical glass fiber assembled on a 3D-printed unit. If needed, multiple probes can be arranged around a single optical fiber. (B) Schematic of the microfluidic neural probe illustrating the probe shank carrying a fluidic channel and recording electrodes, and the probe base interfacing a flexible fluidic tubing and Pl-based ribbon cable. (C) Probe fabrication process based on $\mathrm{cf}-\mathrm{XeF}_{2}$ etching of bulk Si. It illustrates the probe shank cross-sections along lines $A-A^{\prime}$ and $B-B^{\prime}$ in (B). (D) Assembly jig used to attach the PTFE tubing to the fluidic probe and $(E)$ assembly sequence of attaching fluidic tubing to fluidic inlet of Si-based probe. 
configuration has fluidic outlet ports in the lower part of the shank (at $345 \mu \mathrm{m}$ and $445 \mu \mathrm{m}$ from the tip), while the PL configuration has fluidic ports in the upper part of the shank (at $1845 \mu \mathrm{m}$ and $2045 \mu \mathrm{m}$ from the tip). We used an optical glass fiber that is $225 \mu \mathrm{m}$ in diameter and has a numerical aperture of 0.37 at a core diameter of $200 \mu \mathrm{m}$. The tip of the fiber is positioned roughly $100 \mu \mathrm{m}$ above the fluidic ports. The combination of a fiber with either of the two fluidic probe variants allows us to inject and optogenetically target one area (PL or IL) while recording neural activity from both areas.

\subsection{Multifunctional optrode fabrication and assembly}

\section{a. Microfluidic probe}

The fabrication process of the microfluidic probes is schematically summarized in Fig. 1(C). It is carried out on 4-inch, 525- $\mu \mathrm{m}$-thick, single-side polished Si wafers which comprise dry etched alignment marks on the wafer frontside. These marks ensure the precise alignment of multiple photolithography masks used in further processing steps, as detailed below.

Fluidic channel patterning - The wafer frontside and the alignment marks are first covered by a 460-nm-thin stack of high-frequency (HF) $\mathrm{SiO}_{x} / \mathrm{SiN}_{\mathrm{y}} / \mathrm{SiO}_{\mathrm{x}}$ layers with low tensile mechanical stress realized using a plasma-enhanced chemical vapor deposition (PECVD) process. This layer stack serves as a masking layer during the subsequent etching of $\mathrm{Si}$ using $\mathrm{XeF}_{2}$. A linear array of small etch openings (footprint $2 \times 4 \mu \mathrm{m}^{2}$ ) arranged at a pitch of $10 \mu \mathrm{m}$ is transferred into the $\mathrm{SiO}_{x} / \mathrm{SiN}_{\mathrm{y}} / \mathrm{SiO}_{\mathrm{x}}$ masking layer using photolithographically structured photoresist (PR) (AZ1518, MicroChemicals $\mathrm{GmbH}$, Ulm, Germany) and reactive ion etching (RIE), as shown in Fig. 1(C)(i). The PR is not stripped after the RIE sequence and acts as an additional masking layer during the subsequent $\mathrm{cf}-\mathrm{XeF}_{2}$ etching. Before $\mathrm{XeF}_{2}$ etching, the wafers are dipped in $1 \%$ hydrofluoric acid (HF) for $10 \mathrm{~s}$ and dried on a hotplate at $120^{\circ} \mathrm{C}$ for $60 \mathrm{~s}$. This wet etching is essential for removing any RIE process-related residues or native silicon oxide from the etch openings, providing a clean Si surface. The wafers are then directly transferred into the $\mathrm{cf}-\mathrm{XeF}_{2}$ etch system from Memsstar Ltd. (Livingston, UK). This system operates in a continuous-flow configuration, where the nitrogen $\left(\mathrm{N}_{2}\right)$ carrier gas flows continuously through a container comprising $\mathrm{XeF}_{2}$ crystals, thus propelling $\mathrm{XeF}_{2}$ vapor into the etch chamber. The etch chamber maintains a constant pressure of 2.7 mbar during the entire etching process (Drysdale et al., 2015).

The $\mathrm{XeF}_{2}$ vapor isotropically etches $\mathrm{Si}$ through the small etch openings of the masking layer. Once the undercut length exceeds $3 \mu \mathrm{m}$, the adjacent etch fronts merge to form a long channel with a semi-circular cross-section along A-A' while a slightly corrugated channel bottom results along B-B' (Fig. 1(C)(ii)). Etching the wafers for $60 \mathrm{~s}$ results in fluidic channels with a width of $15 \mu \mathrm{m}$. The perforated nature of the thin channel cover prohibits the use of ultrasound-based processes as they would damage these thin dielectric membranes. As a consequence, the PR is next stripped using a plasma-based process.

The cf- $\mathrm{XeF}_{2}$ etching of bulk $\mathrm{Si}$ is followed by the deposition of an 8 - $\mu \mathrm{m}$-thick, stresscompensated HF PECVD $\mathrm{SiO}_{x} / \mathrm{SiN}_{\mathrm{y}}$ layer stack to seal the etch openings (Fig. 2(C)(iii)). This results in the channel sidewalls being covered with the same materials, which terminates once the etch openings are sealed. As a result, the final width of the fluidic channel is reduced from $15 \mu \mathrm{m}$ to about $11 \mu \mathrm{m}$. Despite the fact that $4-\mu \mathrm{m}$-thin layer stacks were found to be sufficiently 
thick to seal the $2 \times 4 \mu \mathrm{m}^{2}$ large etch openings, thicker stacks are applied as they result in a smoother top surface. This is a requirement for reliably patterning the thin metal lines, which interface the electrodes with the contact pads, at minimal width and space values across the sealed channels. A thicker stack also compensates for variations in the deposition rate across the wafer that prevent a precise control of the final thickness of the deposited layer stack.

At this stage, fluidic channels buried in the Si wafer under a planar dielectric layer have been realized. Further steps for electrode patterning and probe shaping are based on the process described elsewhere in detail (Herwik et al., 2009).

Metallization and electrode patterning - Next, bond pads and interconnection lines (line/space $1.5 \mu \mathrm{m} / 1.5 \mu \mathrm{m}$ ) as well as disks at the position of the electrodes are defined by a metal layer stack of titanium (Ti)/gold $(\mathrm{Au}) / \mathrm{Ti}$ (thicknesses $30 / 250 / 30 \mathrm{~nm}$ ). This layer stack is deposited and patterned through evaporation and a lift-off process which is based on the image reversal PR AZ5214E (Microchemicals GmbH, Ulm, Germany) (Fig. 1(C)(iv)). The Ti layers act as adhesion promoters for the dielectric layers, while $\mathrm{Au}$ is applied to minimize the electrical impedance of the interconnection lines. The metal stack is then passivated by depositing another 1.5- $\mu \mathrm{m}$-thick, stress-compensated HF PECVD $\mathrm{SiO}_{\mathrm{x}} / \mathrm{SiN}_{\mathrm{y}}$ layer stack. This passivation is opened at the positions of the electrodes and bond pads using RIE. Next, the underlying Au layer is exposed by etching the top Ti layer in 1\% HF, as illustrated in Fig $1(\mathrm{C})(\mathrm{v})$.

Thereafter, the recording electrodes with a diameter of $30 \mu \mathrm{m}$ are defined by applying a twolayer lift-off process and sputter-depositing a layer stack of Ti/platinum (Pt)/iridium (Ir)/iridium oxide $\left(\mathrm{IrO}_{\mathrm{x}}\right)$ with thicknesses of 30,150, 100 and $200 \mathrm{~nm}$, respectively. The lift-off process applies a combination of the PRs LOR5A (Kayaku Advanced Materials, Westborough, MA, USA) and AZ1518 (Microchemicals GmbH, Ulm, Germany) (Fig. 1(C)(vi)). The Ti and Ir layers serve as adhesion promoters to the underlying passivation and $\mathrm{Pt}$, respectively. The Pt layer acts as the electrode base material, while the $\mathrm{IrO}_{\mathrm{x}}$ coating is implemented to lower the electrode impedance.

Probe patterning - Finally, the etching before grinding (EBG) process (Herwik et al., 2011) is used to realize thin fluidic probe shanks and release them from the Si substrate. First, a combination of photolithography, RIE, and deep reactive ion etching (DRIE) is used to define the in-plane geometry of the microfluidic probes (Fig. 1(C)(vii)). In this process sequence, RIE opens the about 10 - $\mu$ m-thick stack of dielectric layers, while DRIE creates $60-\mu \mathrm{m}$-deep trenches inside the Si wafer. These trenches also provide access to the fluidic channels by defining in-plane inlets and outlets at the probe base and along the probe shaft, respectively. Finally, wafers are ground from the wafer rear to the desired probe thickness of $50 \mu \mathrm{m}$ utilizing the grinding service of DISCO HI-TEC Europe GmbH (Kirchheim, Germany) (Fig. 1(C)(viii)).

Due to the fact that the fluidic inlets and outlets are exposed during the grinding process, any residue entering the channels at these positions potentially results in blocked probe channels. On testing fluidic probes after their assembly, we found that almost $50 \%$ of the probes had blocked channels. We resolved this issue by soaking the unassembled probes in a dimethyl sulfoxide (DMSO) based organic solvent (TechniStrip Micro D350, Microchemicals GmbH, Ulm, Germany), for an extended period of time during which the solvent was occasionally heated to $70{ }^{\circ} \mathrm{C}$. As a consequence of the additional cleaning, more than $90 \%$ of the probes were fluidically functional. Alternatively, we spin-coated PR to the DRIE processed wafer 
frontside prior to grinding. In this way, the channel inlets and outlets are covered by PR to prevent their contamination with fine particles of Si residue. After grinding, probes were soaked as well in TechniStrip Micro D350 for at least one week to ensure a complete removal of PR from the channels. This technique also resulted in over $90 \%$ fluidically functional probes. It is important to note that there are additional reasons for channel blockages observed during testing, such as dust contamination during probe assembly or testing.

\section{b. Optical fiber}

Multimode optical fibers (225 $\mu \mathrm{m}$ diameter, 0.37 NA, Thorlabs, Newton, NJ, USA) were cut with a diamond knife and glued into stainless steel ferrules $(2.5 \mathrm{~mm}$ outer diameter, $230 \mu \mathrm{m}$ bore diameter, Thorlabs) with heat-solidifying epoxy (Precision Fiber Products, Chula Vista, CA, USA). They were polished on one side with $5 \mu \mathrm{m}$ grit silicon carbide paper, $3 \mu \mathrm{m}$ grit aluminum oxide paper and finally $0.3 \mu \mathrm{m}$ grit calcined alumina paper (Thorlabs). The fibers were cut down with a diamond knife to $6 \mathrm{~mm}$ for the PL-configuration and $7.2 \mathrm{~mm}$ for the ILconfiguration probe, so that the tip of the fiber was ca. $100 \mu \mathrm{m}$ above the fluidic ports when assembled next to the microfluidic probe. They were also tested for light transmission by measuring their optical output power with a power meter (Model PM100D, Thorlabs).

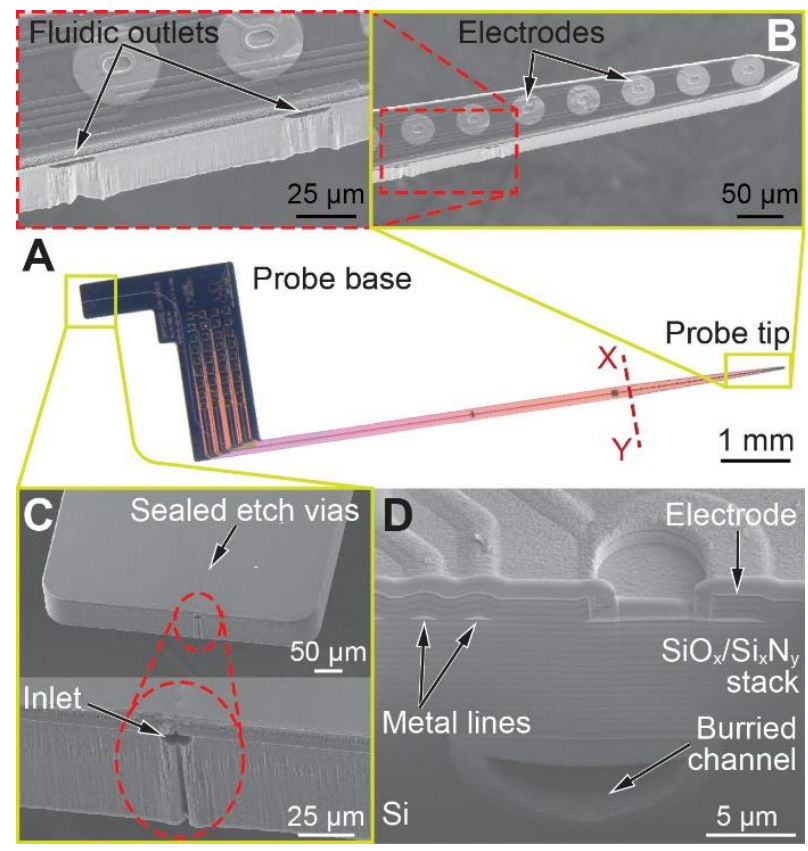

Figure 2: Fabricated 50- $\mu$ m-thick microfluidic probe. (A) Fluidic probe with base and a 7.5-mmlong and maximally 150- $\mu$ m-wide tapered shank. (B) Scanning electron microscopy (SEM) micrographs of probe tip with recording electrodes and fluidic outlets. (C) SEM micrographs of fluidic inlet at the probe base. $(D)$ Cross-section of fluidic probe along $X-Y$ given in $(A)$ realized using focused ion beam (FIB) etching showing the buried fluidic channel in Si as well as metal interconnection lines and electrode over the surface sealed by layer stacks of $\mathrm{SiO}_{x} / \mathrm{SiN}_{y}$

\section{c. Multifunctional optrode assembly}

The assembly process of the multifunctional optrode establishes on the one hand the electrical and fluidic interfaces to the silicon microfluidic probe, and on the other hand the alignment of the assembled probe relative to the ferrule-terminated optical fiber on the 3D-printed unit, as schematically shown in Fig. 1(A). 
Microfluidic probe assembly - First, the microfluidic probe is bonded to a custom-made, highly flexible PI ribbon cable employing a flip-chip-bonder (Fineplacer 96 $\lambda$, Finetech, Berlin, Germany). The ribbon cables with Au-electroplated contact pads are realized, as described in detail elsewhere (Kisban et al., 2009). By applying force, temperature, and ultrasonic power, Au-based contact pads on both the probe base and the cable are joined. The probe-cable interface around the contact pads is underfilled with a two-component epoxy (Epotek 301-2, Epoxy Technology, Billerica, MA, USA) cured at $65^{\circ} \mathrm{C}$ for 2 hours to encapsulate the contact pads against any liquid to which the probe is exposed during the in vivo experiments. Next, a polytetrafluorethylene (PTFE) tubing (inner diameter (ID) $300 \mu \mathrm{m}$, outer diameter (OD) 760 $\mu \mathrm{m})$ is bonded to the in-plane inlet of the probe, enabling fluidic interfacing to the external fluidic equipment, e.g. a syringe pump, for fluidic supply. As initially proposed by Spieth et al. 2009, a short piece of heat-shrinkable (HS) tubing (Raychem MT 2000, Schaffhausen, Switzerland) is used to establish this connection at minimal dead-volume (Spieth et al., 2009). The assembly procedure is carried out using custom-made tools, as schematically illustrated in Fig. 1(D). The protruding part of the probe base and PTFE tubing, surrounded by the HS tubing, are aligned in a straight line (Fig. 1(E)(ii)). By applying the air stream of a hot air gun at $180^{\circ} \mathrm{C}$, the $\mathrm{HS}$ tubing is uniformly shrunk around both the probe inlet and the PTFE tube simultaneously (Fig. 1(E)(ii)). Another epoxy (Epotek 353 ND-T, Epoxy Technology) is applied to fill the remaining gaps around the probe inlet (Fig. $1(\mathrm{E})(\mathrm{iii})$ ). It is cured in an oven at $150^{\circ} \mathrm{C}$ for 1 hour to achieve a leak-proof connection.

Consolidation of fluidic, optical, and electrical units - A 3D-printed cylindrical unit with an external diameter and height of $6 \mathrm{~mm}$ and $5 \mathrm{~mm}$, respectively, is used for aligning and fixing the microfluidic probe and the ferrule-terminated fiber close to each other, as schematically shown in Fig. 1(A). It consists of a 4-mm-deep hollow cavity in the centre to hold the fiber ferrule. During assembly, the microfluidic probe is first aligned and glued near the base of the 3D-printed unit using a UV-curable adhesive (U306, Cyberbond Europe $\mathrm{GmbH}$, Wunstorf, Germany). The ferrule-terminated optical fiber is then inserted into the 3D-printed component. By design of this 3D-printed unit the distance between the frontside of the microfluidic probe and the optical fiber is controlled to a targeted lateral separation of around $200 \mu \mathrm{m}$. The angular misalignment between the fluidic probe shank and optical fiber was determined to be within $2^{\circ}$ and below. The ferrule is secured on both ends of the 3D-printed unit using a self-adhesive resin cement (RelyX Unicem 2, 3M Deutschland, Neuss, Germany). The PI-based ribbon cable is interfaced to a zero insertion force (ZIF) connector on a custommade printed circuit board (PCB) compatible with the applied recording system. The interface is encapsulated with the epoxy Epotek 353 ND-T. The total weight of the implant including the PCB is $0.97 \mathrm{~g}$. Custom holders were designed to assist in this assembly process and storage of the assembled multifunctional optrodes, as illustrated in Fig. S2. 

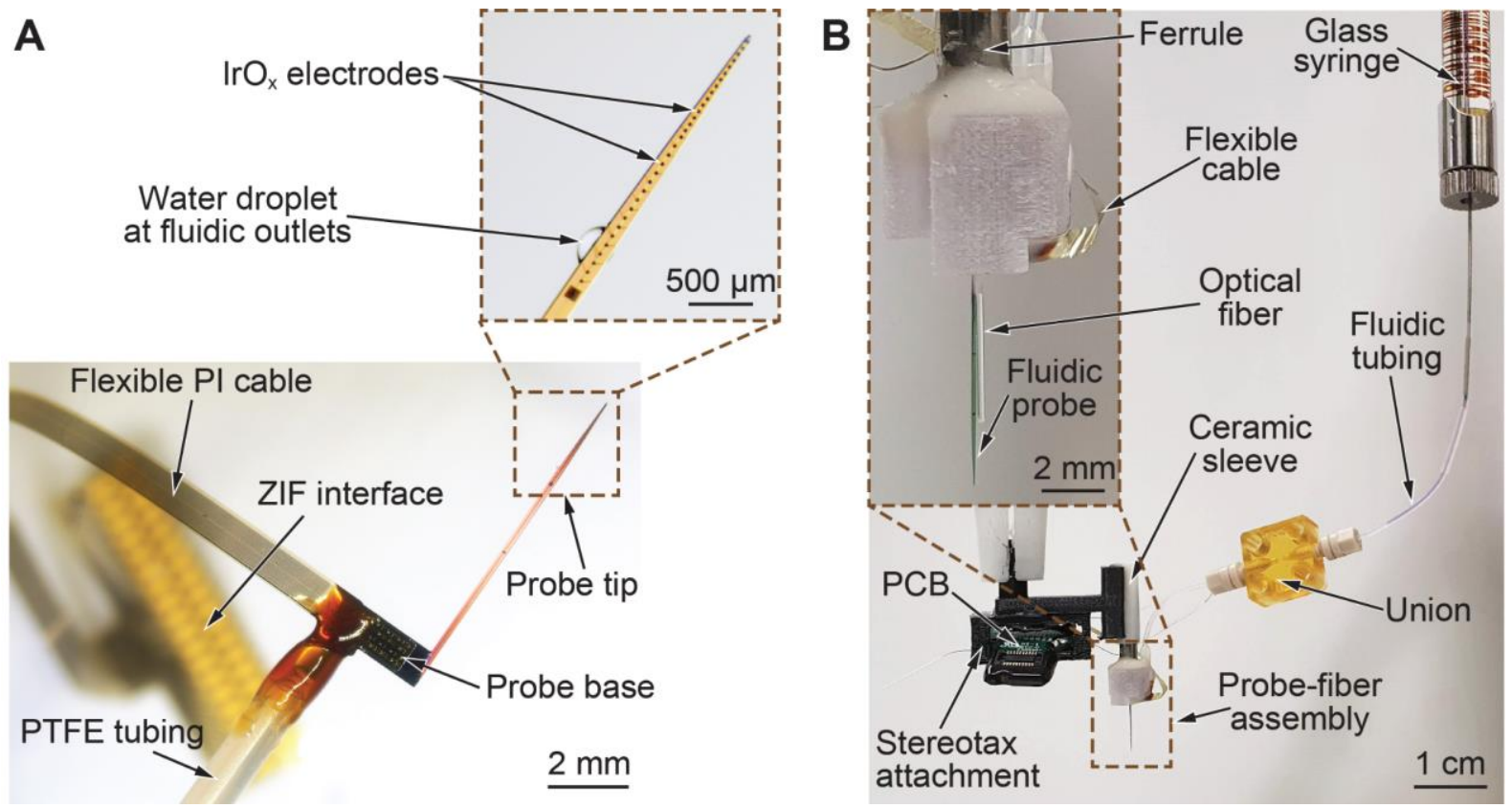

Figure 3: Fabricated fluidic probe and multifunctional optrode: (A) Si-based neural probe assembled to a PTFE tubing and highly flexible PI-based ribbon cable. The fluidic functionality is validated by injecting a small amount of deionized (DI) water through the PTFE tubing. (B) Multifunctional optrode attached to a custom-designed stereotaxic holder. The union is applied as the fluidic interconnection with minimal dead volume between the PTFE tubing of the probe and the tubing interfacing the glass syringe.

\subsection{Electrical and fluidic probe characterization}

The electrical impedance of microelectrodes was measured in Ringer's solution in a twoelectrode setup with a Pt counter electrode in the frequency range from $100 \mathrm{~Hz}$ to $40 \mathrm{kHz}$.

The assembled fluidic probes were in addition hydrodynamically characterized by connecting them to a syringe pump (NE-300-ES, New Era Pump Systems Inc., Farmingdale, NY, USA) using commercially available fluidic connectors. The flow rate was increased from 200 to 1000 $\mathrm{nl} / \mathrm{min}$ in multiple steps, and the fluidic pressure was recorded using a microfluidic pressure sensor (MPS4, Elveflow, France) equipped in the flow path.

In order to investigate the spatial distribution of a liquid injected from these probes as a function of flow rate, we applied $0.6 \%$ agarose gel as a suitable brain model (Z.-J. Chen et al., 2004). The microfluidic probe was connected to a $10-\mu \mathrm{l}$ glass syringe via thin tubings and a union, similar to the fluidic line in the experimental setup in Fig. 3(B). The probe shank was slowly inserted into a block of agarose gel, and $1 \mu \mathrm{l}$ of $0.22-\mu \mathrm{m}$-filtered, $0.1 \%$ bromophenol blue solution was injected using the syringe pump NE-300-ES (New Era Pump Systems Inc.). Multiple injections were performed at flow rates of 50,100, 200, and $400 \mathrm{nl} / \mathrm{min}$, and the spread of dye was monitored with a microscope camera (MC190 HD, Leica Microsystems $\mathrm{GmbH}$, Wetzlar, Germany). 


\subsection{In vivo experiment}

\section{a. Nanosyringe liquid loading}

A $10 \mu \mathrm{l}$ nanosyringe (World Precision Instruments, Sarasota, FL, USA) is first filled with the fluid to be injected before connecting it to the fluidic line of the multifunctional optrode. Since the combined volume of the syringe and the interconnection tubing is much larger than the required injection volume, the syringe is first filled with a saline solution. For this, a 28 gauge microfil (World Precision Instruments) was used to load $7 \mu$ l of colored saline into the nanosyringe. A 40-mm-long PTFE tubing (ID $300 \mu \mathrm{m}$, OD $760 \mu \mathrm{m}$ ) was then attached to a 26 gauge nanosyringe needle (World Precision Instruments) using a heat shrinkable tubing. The tube-fixed needle was then inserted into the nanosyringe which was then loaded into the stereotaxic holder of the microsyringe pump (World Precision Instruments). The saline solution was pushed to the tip of the PTFE tubing. Next, the subsequent solutions were withdrawn in the following order at $200 \mathrm{nl} / \mathrm{min}$ : 1 microliter of corn oil (to prevent the injection fluid from mixing with the saline), $800 \mathrm{nl}$ of the desired injection fluid (in this study bicuculline or ChR2 virus), and $200 \mathrm{nl}$ of air. The open end of the tubing was closed with a silicone cap, and the microsyringe was stored at $4^{\circ} \mathrm{C}$ until surgery on the following day.

\section{b. Nanosyringe connection to multifunctional optrode}

The tubings from the nanosyringe and the multifunctional optrode were linked via an interconnect union and fittings (LabSmith, Inc., Livermore, CA, USA). Once connected (Fig. $3(B)$ ), we injected through the nanosyringe in air at a rate of $200 \mathrm{nl} / \mathrm{min}$ until a drop of the injection fluid appeared at the outlet of the fluidic probe. We stopped the injection immediately, and removed the drop with a kimtech wipe.

\section{c. Stereotaxic surgery for acute recording}

All animal related procedures were in accordance with the guideline RL $201063 \mathrm{EU}$ and were approved by the Regierungspräsidium Freiburg (approval number TVA G-15-11 and TVA G20-26). We kept the rats in a reversed 12-hour light cycle, and without any food or water deprivation.

Animals were given an inhalative gas anesthesia with isoflurane using oxygen $\left(\mathrm{O}_{2}\right)$ as a carrier gas. They were then administered intraperitoneal (i.p.) injections of $40 \mathrm{mg} / \mathrm{kg}$ ketamine and $0.1 \mathrm{mg} / \mathrm{kg}$ medetomidine. Subcutaneous (s.c.) injections of $5 \mathrm{mg} / \mathrm{kg}$ carprofen and $0.05 \mathrm{mg} / \mathrm{kg}$ buprenorphine were applied prior to surgery. A post-surgery additional injection of carprofen was also applied. Anesthesia was maintained at $0.5-2 \%$ isoflurane and $0.5 \mathrm{l} / \mathrm{min} \mathrm{O}_{2}$. To prevent hypothermia, rats were kept on a heating pad and their temperature was monitored via a rectal sensor. Eyes were kept moist with an ophthalmic ointment (Bepanthen, Bayer Health Care, Leverkusen, Germany). Rats were injected s.c. with $3 \mathrm{ml}$ of saline solution every two hours to maintain their fluid balance. Fur was shaved from the surgical site, and the rats were then head-fixed into a stereotaxic frame (World Precision Instruments,). The surgical surface was disinfected with Braunol (B. Braun Melsungen AG, Melsungen, Germany), followed by Kodan (Schülke, Norderstedt, Germany). A single 2-cm-long incision was made down the skull from anterior to posterior, and the edges of the skin were held apart with surgical clamps. A bone scraper was used to remove the skin tissue from the skull, and $3 \%$ hydrogen 
peroxide was used to thoroughly clean the skull of any leftover debris or tissue. The head was then levelled in the anterior-posterior (AP) direction so that bregma and lambda were within a $0.05 \mathrm{~mm}$ height difference of each other. Medial-lateral (ML) levelling was achieved by positioning the head so that ML locations to the right and left of bregma were within $0.05 \mathrm{~mm}$ of each other. A craniotomy was drilled around the area of planned injection. One miniature self-tapping screw (J.I. Morris Company, Southbridge, MA, USA) was inserted deep through the skull to serve as a grounding element.

The multifunctional optrode was connected to the stereotaxic frame via a custom designed 3D-printed stereotaxic attachment that is held by a stereotaxic cannula holder (World Precision Instruments) (Fig. 3(B)). A ceramic mating sleeve (2.5 mm diameter, Thorlabs) was glued on one end of the stereotaxic attachment. The ferrule of the multifunctional optrode was inserted into the ceramic sleeve, and the PCB was placed into a slot in the stereotaxic attachment (Fig. $3(B))$. A duratomy was made over the injection site, and the ground wire from the PCB was attached to a skull screw. Next, we attached the PCB to a 32-channel data acquisition system using a ZIF-clip headstage (Tucker-Davis Technologies (TDT), Alachua, FL, USA), and inserted the probe to the desired location (AP $3.24 \mathrm{~mm} / \mathrm{ML} 1.0 \mathrm{~mm} / \mathrm{DV}-4.2 \mathrm{~mm}$ from surface of brain).

\section{d. Acute recordings with bicuculline application}

After inserting the probe into the brain, we waited for the tissue to settle around the probe for 5 minutes. We injected $200 \mathrm{nl}$ of $5 \mathrm{mM}$-(-) bicuculline methiodide (Tocris Bioscience, Bristol, UK) with the syringe pump at $100 \mathrm{nl} / \mathrm{min}$. We recorded before, during, and after the injection to observe the neural effect of the fluidic drug. Recording was performed using a 32-channel data acquisition system (TDT) and filter settings of $300 \mathrm{~Hz}$ for high-pass and $5 \mathrm{kHz}$ for lowpass filtering. We acquired neural data with a sampling frequency of $F_{s}=24,414.0625 \mathrm{~Hz}$. After recording, the probe was retreated from the brain and the rat was perfused.

\section{e. Chronic implantation}

The surgery was similar to the surgery method for the acute recording. Along with one miniature screw for grounding, we placed 4 additional screws into the skull to provide an anchor for the implantation cement. We implanted the probe to the desired depth, and injected $500 \mathrm{nl}$ of pAAV-hSyn-hChR2(H134R)-eYFP-WPRE (University of North Carolina Vector Core, Chapel Hill, NC, USA) at a flow rate of $100 \mathrm{nl} / \mathrm{min}$. Silicone elastomer (Kwik-Cast, WPI, Sarasota, FL, USA) was placed into the craniotomy to prevent brain swelling. We then applied a thin layer of super bond C\&B cement (Sun Medical Co., LTD, Moriyama City, Shiga, Japan) between one of the skull screws and around the probe to stabilize the probe in the brain. The PTFE tubing attached to the fluidic probe was cut at the base, and the opening of the tubing was blocked with dental cement. The PCB board was placed at a $40^{\circ}$ angle to the base of the skull, and fixed with Paladur (Heraeus, Hanau, Germany). Paladur was further added to create a firm base on the skull. The surgical site was sealed around the implant by interrupted sutures. Rats were fed $5 \mathrm{mg}$ carprofen pellets for three days after surgery, and it was checked during these days that they did not drop to under $80 \%$ of their pre-surgery, ad libitum-food and -water access weight. We waited 6 weeks post-surgery for sufficient viral expression before stimulation experiments.

\section{f. Recording and optogenetic stimulation in freely moving animals}


The rat was placed in a behavioral box for freely moving exploratory behavior. The box was made from 8-mm-thick acrylic glass and had a size of $45 \times 36 \times 55 \mathrm{~cm}^{3}$. For neuronal recordings, broadband signals were simultaneously recorded via ZD32 digital head stages connected via an electrical commutator (ACO64, TDT) to the recording controller (Intan Technologies LLC, Los Angeles, CA, USA). Neural data was recorded at a sampling frequency of $30 \mathrm{kHz}$. For optogenetic stimulations we connected the rat via a mono mode fiber-optic patch cord to a light source (LightHUB compact laser combiner, OMICRON Laserage, Rodgau-Dudenhofen, Germany) to stimulate with $473 \mathrm{~nm}$ pulsed light (5-ms-wide pulses at 10-40 Hz, 1-s-long bursts, $318 \mathrm{~mW} / \mathrm{mm}^{2}$ ) while recording neural activity from the transfected and the adjacent non-transfected area.

\subsection{Data analysis and histology}

\section{a. Analysis of electrophysiological recordings}

We performed the analysis using custom written Python scripts. The broadband signal was high-pass filtered (4. degree butterworth digital, $200 \mathrm{~Hz}$ cutoff using scipy.signal.sosfiltfilt). The resulting signal was median subtracted across channels (using 4 channel rolling median window). We defined spikes as time points exceeding $4^{*}$ std of the median subtracted signal. Spike times were aligned relative to the laser bursts and increase in the firing rate was calculated relative to $1 \mathrm{~s}$ period before the laser stimulation. Firing rate was obtained via convolution of the spike times with a Gaussian window. We assessed significance of the modulation of the firing rate via the Bonferroni adjusted ranksum test with prestimulus vs peri stimulus firing rate. For the analysis of neural recordings with bicuculline injection spikes were detected in the same manner directly on high-pass filtered signal; here LFP and spike times were aligned to the start of injection.

\section{b. Perfusion and histology}

Animals were sacrificed via an i.p. injection of $400 \mathrm{mg} / \mathrm{kg}$ sodium pentobarbital (Release ${ }^{\circledR} 500$, WDT, Garbsen, Germany) and a transcardial perfusion of $4{ }^{\circ} \mathrm{C}$ PBS, followed by ice-cold $4 \%$ paraformaldehyde. The brains were removed and post-fixed for 1-2 days and then transferred to $30 \%$ sucrose (Merck KGaA, Darmstadt, Germany) dissolved in PBS, and stored at $4{ }^{\circ} \mathrm{C}$. After the brains were fully saturated with sucrose, we sectioned them into $50-\mu \mathrm{m}$-thin slices on a sliding microtome (Leica model SM2010 R, Leica Biosystems Nussloch GmbH, Nussloch, Germany). Images were obtained on an Axioplan 2 Imaging microscope.

\section{Results}

\subsection{Microfluidic probe fabrication and characterization}

\section{a. Probe fabrication and assembly}

Figure 2(A) shows a 50- $\mu$ m-thick processed microfluidic probe after release from the grinding tape. The pronounced color difference between probe base and shank is due to the high density of interconnecting lines along the shank. Details of the tapered shank tip with the $\mathrm{IrO}_{\mathrm{x}}$ 
electrodes and the fluidic outlet ports are provided in the scanning electron microscopy (SEM) micrographs in Fig. 2(B\&C). Both outlet ports shown in the inset of Fig. 2(B) are connected to a single fluidic channel. The array of sealed etch openings above this fluidic channel are clearly visible in Fig. 2(C). Figure 2(D) illustrates the cross-section of the probe tip along $X-Y$, as indicated in Fig. 2(A), generated by focused ion beam (FIB) etching. It reveals an $11-\mu \mathrm{m}$-wide fluidic channel in the $\mathrm{Si}$ substrate buried under a $10-\mu \mathrm{m}$-thick stack of $\mathrm{SiO}_{x} / \mathrm{SiN}_{\mathrm{y}}$, as well as interconnection lines under the topmost passivation stack, and the via between metallization and the $\mathrm{IrO}_{\mathrm{x}}$ electrode. For FIB processing, the probe surface has been covered by a protective layer made of $\mathrm{Pt}$ and carbon.

An assembled microfluidic probe with PTFE tubing and PI ribbon cable is shown in Fig. 3(A). It clearly indicates the high flexibility of the cable and shows in the background its ZIF interface to be connected to the probe PCB (Fig. 3(B)). The two sets of electrodes arranged at pitches of 60 and $85 \mu \mathrm{m}$ are easily distinguished in the inset of panel $A$. The fluidic functionality of the Si-based neural probe is proven by injecting water through the fluidic channel that forms a small droplet around the two fluidic outlets.

A completely assembled, multifunctional optrode attached to a custom-designed holder for the stereotaxic arm is shown in Fig. 3(B). A connection with a low dead volume between the microfluidic probe and the glass syringe is realized using thin PTFE tubings (ID $300 \mu \mathrm{m}$, OD $760 \mu \mathrm{m})$ and an interconnect union.

\section{b. Electrical characterization}

Figure 4(A) summarizes the absolute impedances $|Z|$ of a sample of 16 electrodes of a 32 channel probe measured over the frequency range from $100 \mathrm{~Hz}$ to $40 \mathrm{kHz}$. The $30-\mu \mathrm{m}$-large circular $\mathrm{IrO}_{\mathrm{x}}$ electrodes show on average a $|Z|$ value of $168 \pm 9 \mathrm{k} \Omega(\mathrm{n}=32)$ at a frequency of $1 \mathrm{kHz}$.

\section{c. Fluidic characterization}

Figure 4(B) shows a representative pressure measurement as a function of flow rate for a probe with an 11- $\mu \mathrm{m}$-wide and 9.6-mm-long channel. As expected for a laminar flow inside the PTFE tubing and the probe channel, the relationship between the flow rate and measured

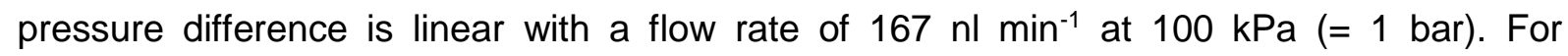
applications which require a higher flow rate per applied pressure, the size of microfluidic channels can be increased during fabrication by a prolonged $\mathrm{XeF}_{2}$ etching time.

\section{d. In vitro injections into agarose gel}

Snapshots of dye distribution after injecting 100,200,500, and $1000 \mathrm{nl}$ of dye at flow rates of $50,100,200$, and $400 \mathrm{nl} / \mathrm{min}$ are shown in Fig. 4(C). At a low flow rate of $50 \mathrm{nl} / \mathrm{min}$, the dye distribution around the two channel outlets is mainly isotropic and largely dominated by diffusion. In contrast, a significant backflow along the shank is observed for the highest flow rate of $400 \mathrm{nl} / \mathrm{min}$. At the intermediate flow rates of 100 and $200 \mathrm{nl} / \mathrm{min}$ a moderate backflow resulting in a slightly elliptical dye distribution can be noticed. 

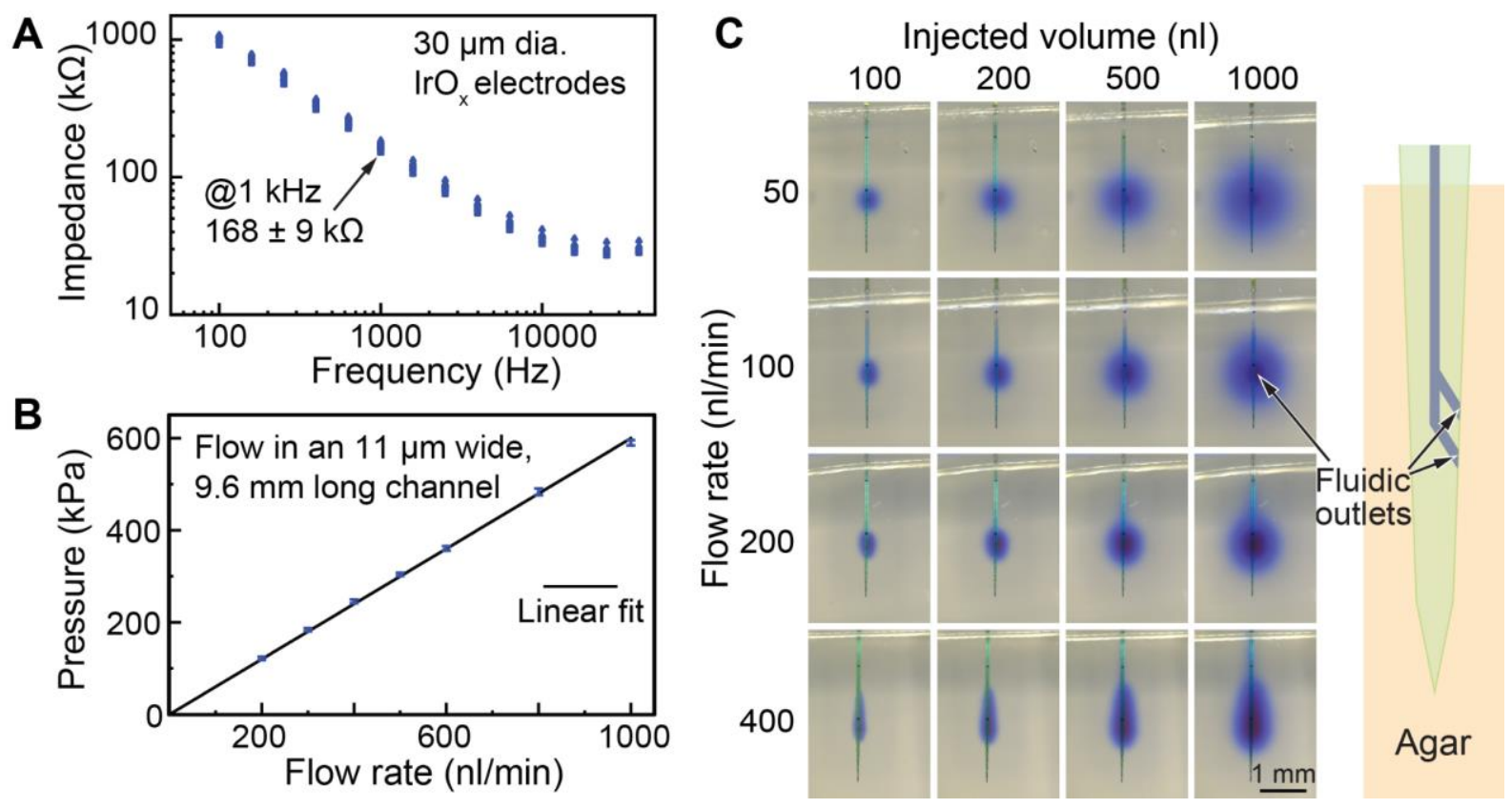

Figure 4: (A) Absolute impedance $|Z|$ of a sample of $16 \mathrm{IrO}$ electrodes of a 32-channel probe measured in saline. The mean value of all electrodes $(n=32)$ at $1 \mathrm{kHz}$ is $168 \pm 9 \mathrm{k} \Omega$. (B) Pressure measured in the fluidic tubing as a function of applied flow rate for a probe with an 11- $\mu \mathrm{m}$-wide and 9.6-mm-long microfluidic channel. (C) Injections of dye in agarose gel at different flow rates to observe liquid distribution. Pictures just after injecting 100, 200, 500, and $1000 \mathrm{nl}$ of dye are presented for each flow rate. Fluidic outlets open to the right of the probe, as shown in the probe schematic on the right.

\subsection{In vivo experiments}

\section{a. Observation of in vivo neuromodulation via bicuculline application in an anesthetized rat}

In order to demonstrate the injection via the fluidic channel and the electrophysiological recording in vivo, we locally injected a pharmacological agent known to induce a strong effect on neural activity. An acute implantation was performed, with bicuculline injected while recording neural activity with the fluidic probe. We observed a clear increase in neural activity after the injection (Fig. 5). This is in line with the well-characterized effect of bicuculline, which as a GABA receptor antagonist, causes increased neural activity and epileptic seizures (Huffman \& McFadin, 1972; Pongrácz et al., 2013). The increase in activity started shortly after injection (20-70 s post-injection). This is comparable to the results of Pongrácz et al., who also found the effect to start quickly (30-60 s) post-injection (Pongrácz et al., 2013). Temporally, the increase in neural activity gradually developed from channels closest to the fluidic ports, to those farthest away. This effect could be either due to diffusion of the drug away from the port or from activated units recruiting distal neurons in synchronized seizure activity. 
A

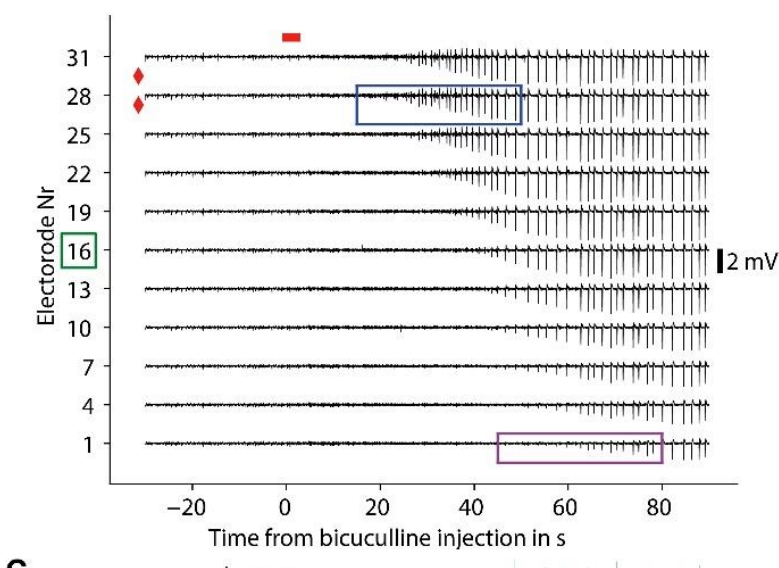

C

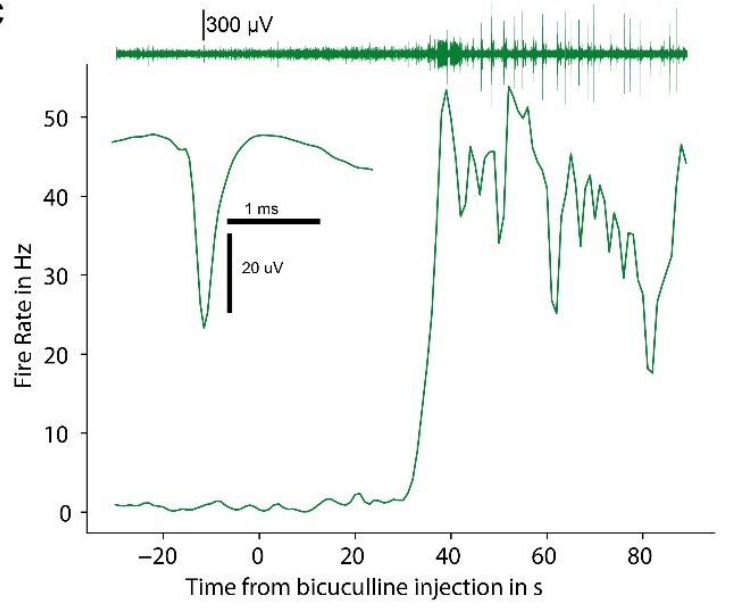

B

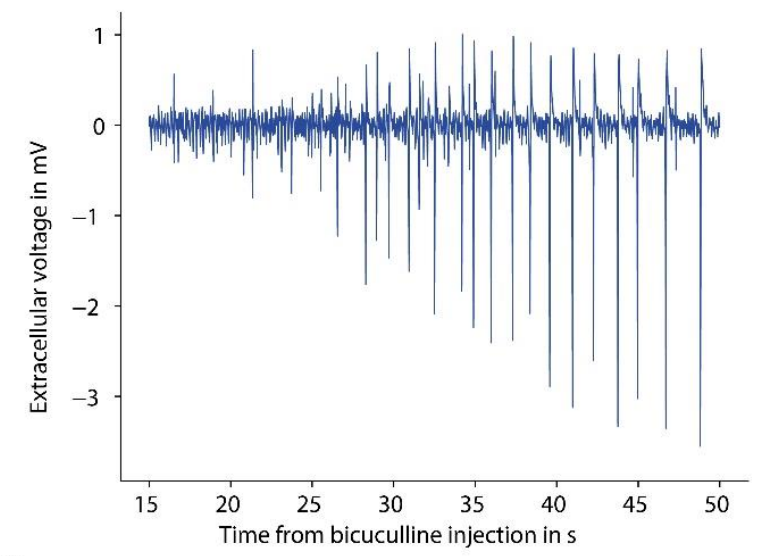

D

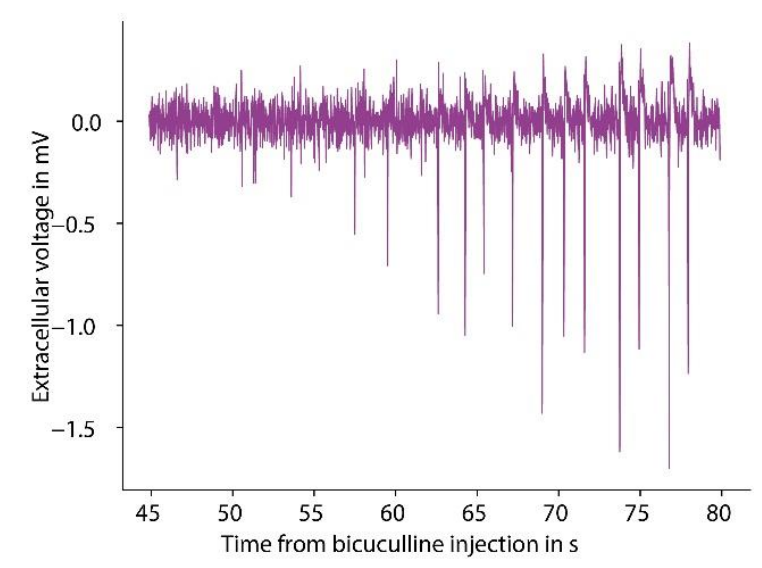

Figure 5: Acute implantation and bicuculline injection. (A) LFP activity measured with electrodes spanning the distance $390 \mu \mathrm{m}$ (electrode 32) and $1.9 \mathrm{~mm}$ (electrode 1) from the injection site. The red diamonds represent the fluidic port location, the red rectangle represents the time span of injection. We observed epileptic activity shortly after the injection starts at all electrodes. (C) Firing rate of a neuron recorded from channel 16 before and after the bicuculline injection. The firing rate increases $\sim 30$ s post-injection. (B\&D) Selected close-ups from panel A; LFP from channels 28 and 1. The increase in activity occurs earlier in channel 28 ( 25 s post-injection) compared to channel 1 ( 55 seconds post-injection).

\section{b. Observation of in vivo neuromodulation via optogenetic activation in a freely moving rat}

As ChR2 is a relevant tool for interrogating neural circuits in behavioral experiments (Tye \& Deisseroth, 2012), we tested the feasibility of the multifunctional optrode for chronic implantation with viral injection of ChR2, optogenetic stimulation and electrophysiological recording. We applied PL-configured optrode, which has two injection ports and one fiber targeting PL, and recording electrodes equally distributed in both PL and IL. ChR2 was injected through the microfluidic channel of the probe during the implantation surgery. After waiting for sufficient viral expression (6 weeks), we recorded from the chronically implanted rat during blue light stimulation. We observed neural responses to blue light stimulation. As expected by stimulating ChR2 expressing neurons, there was a significant increase in the firing rate (Wilcoxon-signed rank test, Bonferroni adjusted, $p<0.001$ ) in neural signals collected from electrodes 22-26 (Fig. 6(F)). This response was restricted to units near the upper parts of the 
bioRxiv preprint doi: https://doi.org/10.1101/2021.04.30.441836; this version posted April 30 2021. The copyright holder for this preprint (which was not certified by peer review) is the author/funder, who has granted bioRxiv a license to display the preprint in perpetuity. It is made available under aCC-BY-NC-ND 4.0 International license.

shank (spanning $510 \mu \mathrm{m}$ ). This is expected; viral expression should be centered at the injection region near the fluidic outlets (at $1845 \mu \mathrm{m}$ and $2045 \mu \mathrm{m}$ from the tip). Histological analysis of the viral expression (Fig. 6(D)) also confirmed a small area of expression (ca. $600 \mu \mathrm{m}$ dorsoventral spread), comparable to the range of ChR2-responding units found from the neural recording. A further restriction of optogenetic activation was accomplished by the fiber placement, which allowed targeted light stimulation to the upper area of the shank. We also tested different stimulation frequencies. We observed a slight increase in firing rate from responding units when stimulating with higher frequencies up to $40 \mathrm{~Hz}$, which is expected since ChR2 firing rate can follow stimulation frequencies up to $40 \mathrm{~Hz}$ (Grossman et al., 2011; Jackman et al., 2014).

\section{c. Histology reveals spatially precise expression pattern}

Histological analysis confirmed viral injection to PL. We observed eYFP expression around the target area of injection (Fig. 6(D)) spreading over an area of ca. $0.6 \mathrm{~mm}^{2}$ (DV spread .6 $\mathrm{mm}, \mathrm{ML}$ spread $1 \mathrm{~mm}$ ) in a $50 \mu \mathrm{m}$ slice taken from anterior-posterior position of $+3.7 \mathrm{~mm}$ to Bregma. Since the eYFP was injected via the viral construct that also contains ChR2, areas that express eYFP should indicate areas that also express the excitatory opsin ChR2. Notably, there was no backflow observed, as sometimes seen with traditional injection methods (Fig. S1). The small dorsoventral spread (ca. $600 \mu \mathrm{m}$ ) of opsin expressing neurons was in line with findings from the stimulation and recordings. As there was only viral expression in a restricted area of the brain, it was expected that only these opsin-expressing neurons positioned adequately near the fiber tip would respond to blue light stimulation. 
bioRxiv preprint doi: https://doi.org/10.1101/2021.04.30.441836; this version posted April 30, 2021. The copyright holder for this preprint (which was not certified by peer review) is the author/funder, who has granted bioRxiv a license to display the preprint in perpetuity. It is made available under aCC-BY-NC-ND 4.0 International license.

A

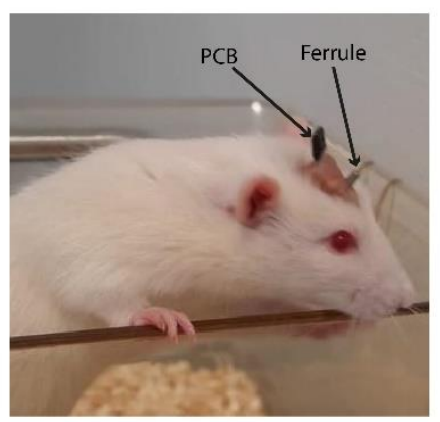

D

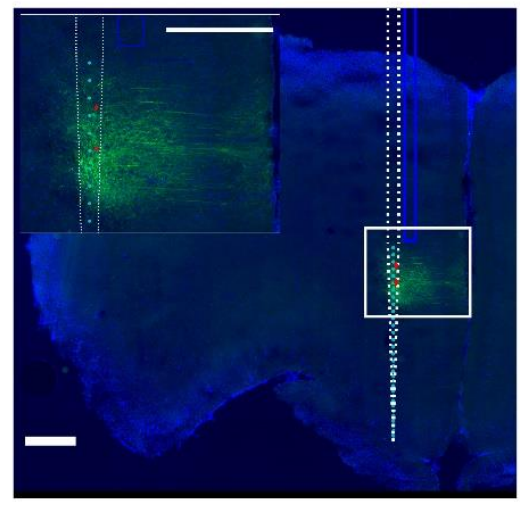

G
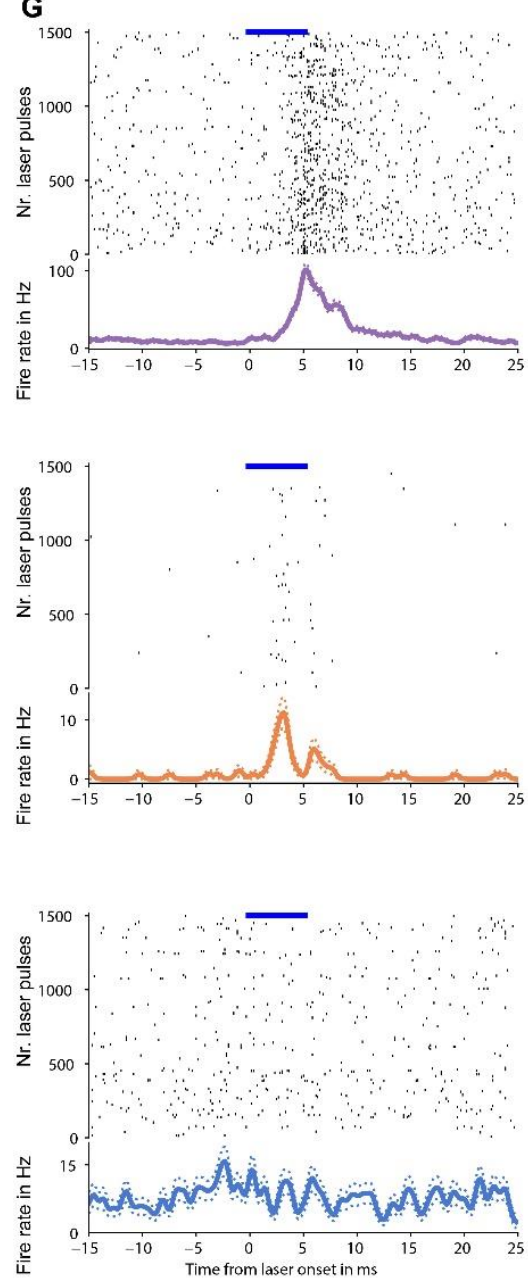

B

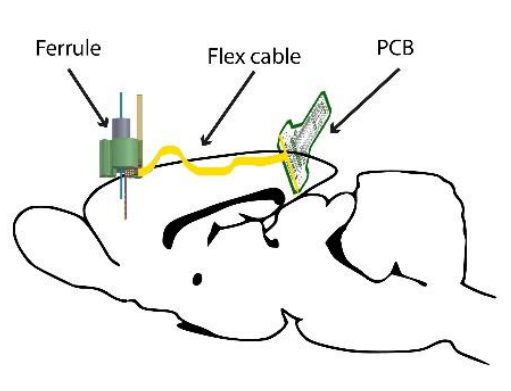

C

PL
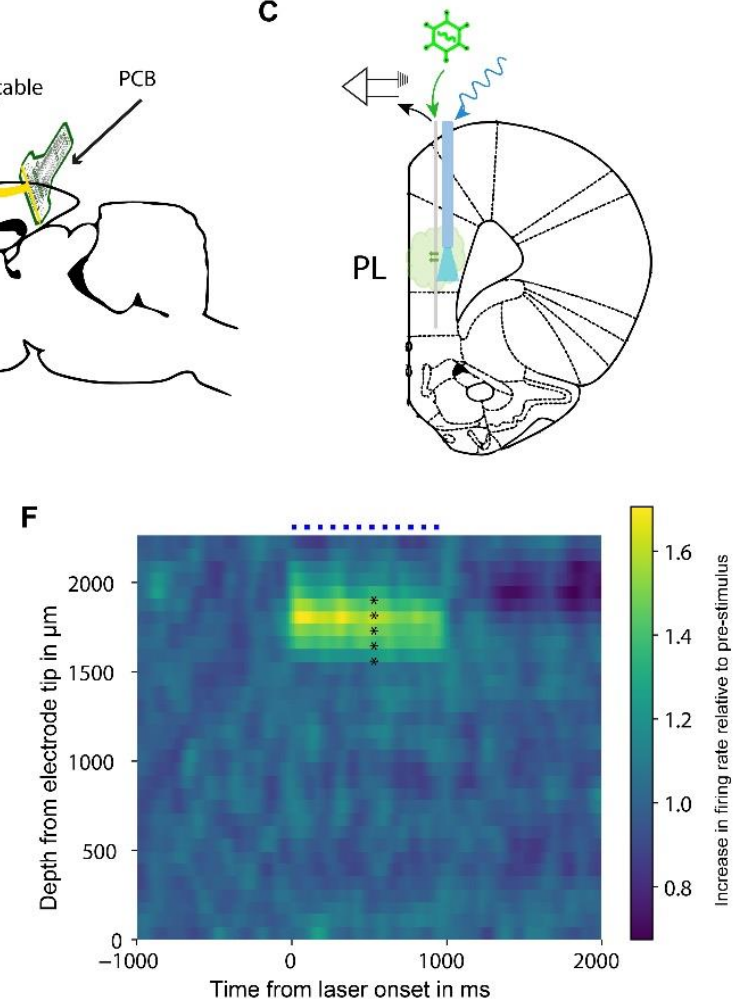

H I
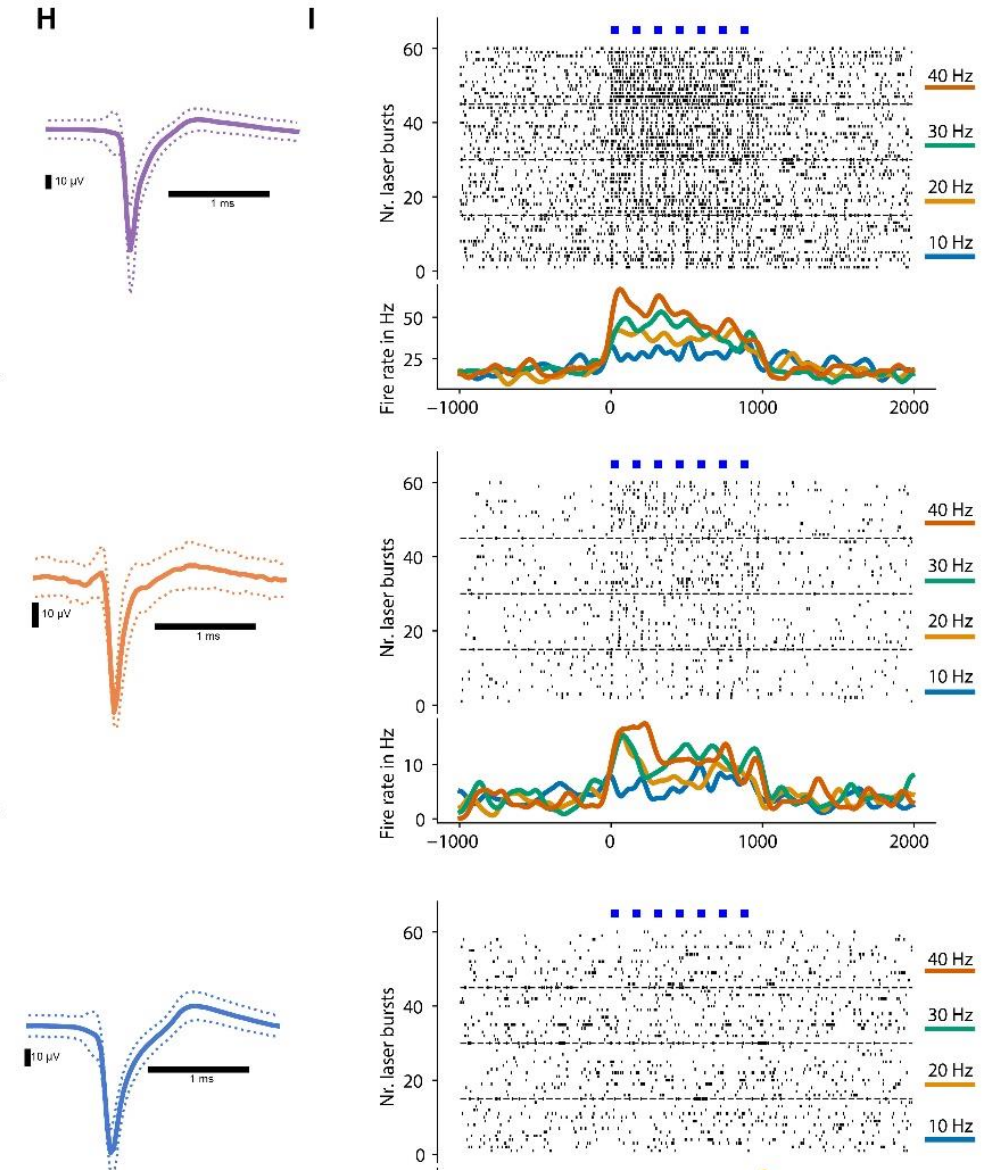

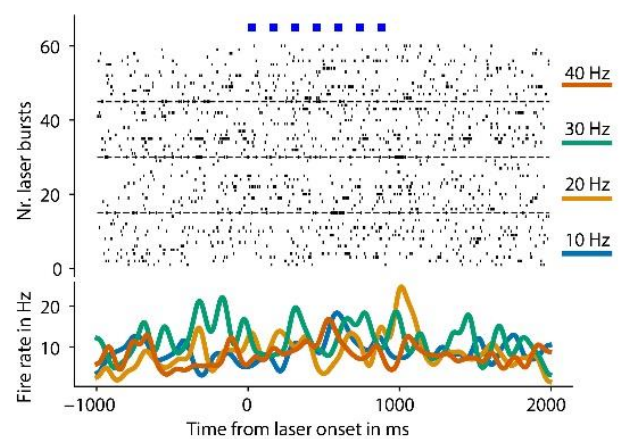


Figure 6A-I: Chronic implantation and optogenetic stimulation: (A) Wild-type Sprague Dawley rat implanted with the fluidic optrode, 1 week post-implantation. The implant has comparable size to a conventional electrode or fiber implantation. The PCB is cemented at roughly a $40^{\circ}$ angle onto the posterior part of the skull. (B) Configuration of the implant elements on the rat skull. The 3D assembly unit, the lower part of the ferrule, flex cable, and PCB board (until the ZIF connector) are embedded in dental cement. (C) Schematic of the viral injection, light activation and recording in mPFC. (D) Histology of a rat chronically implanted with a PLconfiguration multifunctional optrode, which was injected via the fluidic probe with AAV5-hSynChR2-eYFP. Scale bar $=500 \mu \mathrm{m}$. We observed a well-restricted area labelled with eYFP. The inset represents a close-up of the eYFP (representing opsin)-expressing area, with welllabelled cell bodies. (E) Schematic of the probe used for chronic implantation; the fiber is shown in blue next to the probe shank, with fluidic ports represented by red diamonds and electrodes shown in cyan. $(F)$ Overview of neural activity with light stimulation, showing the increase in firing rate relative to $1 \mathrm{~s}$ pre-stimulation; * indicates electrodes with significant change of spiking activity There was an optogenetic response to blue light pulsed stimulation (1s bursts of $5 \mathrm{~ms}$ wide pulses represented by blue dots), which is restricted to the upper electrodes on the probe shank, located in the PL (matching the observed area of expression in Fig. 6(D)). (H\&l) Spiking activity and waveforms of units recorded from channel 26, 24 and 19 (highlighted in Fig. 6(E) in respective colors), which was located in the PL of a freely moving rat. Channels 26 and 24 (purple and orange) are example units which showed an optogenetic response to 5-ms-wide blue light pulses. Such units were observed in several electrodes located in PL. The lower part of the shank (example unit recorded from channel 19 shown in blue) did not show an optogenetic response. Injection and stimulation was well restricted to the target area. (I) Comparison of the firing rate of units recorded from channel 26, 24 and 19 when stimulated with frequencies of $10,20,30$ or $40 \mathrm{~Hz}$. We observed a greater effect on firing rate for higher frequency stimulation on the optogenetically activated units (shown on channels 26 and 24).

\section{Discussion and conclusions}

In this paper, we presented a multifunctional optrode comprising a silicon-based microfluidic neural probe arranged close to an optical glass fiber in a miniature assembly. The microfluidic probe is equipped with an $11-\mu \mathrm{m}$-wide fluidic channel, and $32 \mathrm{IrO}_{\mathrm{x}}$-based recording electrodes (diameter $30 \mu \mathrm{m}$ ) on a tapered probe shank with a length, thickness, and maximum width of $7.5 \mathrm{~mm}, 50 \mu \mathrm{m}$, and $150 \mu \mathrm{m}$, respectively. Our technology enables high spatial specificity between fluidic ports and recording electrodes, with the freedom to control their size and position according to the application. Without any modification in the process, one can extend the probe design to a multi-shank array with multiple fluidic channels in the desired configuration. The use of a standard optical fiber as a waveguide facilitates the use of a wide range of optical wavelengths and power amplitudes. All elements of our multifunctional optrode are easily interfaced to external devices using commercial connectors. Optical connection to the fiber is achieved via a ferrule, electrical connection to the recording system via a TDT ZIFclip connector on a custom-made PCB, and fluidic connection to a syringe via standard fluidic connectors.

With a modest total weight of $0.97 \mathrm{~g}$, the system is suitable for chronic implantations in rodents. We demonstrated the utility of our multifunctional optrode for injecting a viral vector through 
the integrated microchannel, chronic implantation for several weeks to lend sufficient time for viral expression, and photostimulating neurons near the injection site while recording neural activity both at and adjacent to the injection area in an awake freely moving rat. We measured several units which responded to light stimulation, while units outside the injection area showed no response. The units which responded to an optical stimulation reflected the opsinexpressing area found in the histological analysis. The histology of this implanted rat showed a specific and restricted area of infection, which can prove advantageous to other injection methods which can result in larger viral spread post-injection. This advantage is attributed to small fluidic injection ports, and the integration of an injection modality into the optrode enabling a single insertion surgery for optogenetics. We established the multifunctional optrode as a tool for specific viral injection and optogenetic manipulation with electrophysiological recording in freely moving animals.

Fluidic channels can also be employed to apply anti-inflammatory drugs which may improve the longevity of chronic recordings, or to apply pharmacology while performing optogenetic experiments and allow for various constellations of technical applications. We demonstrated a pharmacological application with our microfluidic probe via local injection of the GABA antagonist bicuculline in an anesthetized rat, and measured its effect on neuronal activity by recording before, during and after the injection. As a proof of principle, we demonstrated an expected bicuculline effect that occurred first at units near the point of injection, and with time spread to units farther away.

Our multifunctional optrode uses standard glass fibers as a suitable light guide. However, these fibers (diameter $225 \mu \mathrm{m}$ ) are larger than our tapered microfluidic probe (maximum $150 \times 50 \mu \mathrm{m} 2$ ). Using smaller diameter fibers (Eriksson et al., 2021) or incorporating waveguides (Schwaerzle et al., 2017) on the microfluidic probe would further reduce the brain damage but might come at the cost of higher optical losses and lower output power. Integration of light sources such as LEDs (Ayub et al., 2020; Wu et al., 2015) or laser diodes directly on the microfluidic probe would further enhance the versatility of our device and would facilitate scaling the system to multiple light sources while maintaining a small implant size.

\section{Acknowledgements}

The research leading to these results has partly received funding through the DFG-funded Priority Programme SPP 1926 (Next Generation Optogenetics) under grant number RU 869/51 and DI 1908/6-1, and the BrainLinks-BrainTools, Cluster of Excellence funded by the German Research Foundation (DFG, grant number EXC 1086). The authors gratefully acknowledge technical support by the RSC team at the Department of Microsystems Engineering (IMTEK) regarding cleanroom fabrication, the Laboratory for Nanotechnology at IMTEK for valuable help with SEM imaging, and the Freiburg Center for Interactive Materials and Bioinspired Technologies (FIT) for focused ion beam preparation. 


\section{Authors contribution}

Conceptualization, P.R. and I.D.; Methodology, K.S. and Z.J.; Analysis, K.S., Z.J., A.S.; Investigation, K.S., Z.J. and A.S.; Writing - Original Draft, K.S. and Z.J.; Writing - Review \& Editing, P.R., O.P. and I.D.; Visualization, K.S., Z.J. and A.S.; Supervision, P.R., O.P. and I.D.; Funding Acquisition, P.R. and I.D.

\section{References}

Ayub, S., David, F., Klein, E., Borel, M., Paul, O., Gentet, L., \& Ruther, P. (2020). Compact optical neural probes with up to 20 integrated thin-film $\mu$ LEDs applied in acute optogenetic studies. IEEE Transactions on Biomedical Engineering, 1-1. https://doi.org/10.1109/TBME.2020.2966293

Boyden, E. S., Zhang, F., Bamberg, E., Nagel, G., \& Deisseroth, K. (2005). Millisecondtimescale, genetically targeted optical control of neural activity. Nature Neuroscience, 8(9), 1263-1268. https://doi.org/10.1038/nn1525

Canales, A., Jia, X., Froriep, U. P., Koppes, R. A., Tringides, C. M., Selvidge, J., Lu, C., Hou, C., Wei, L., Fink, Y., \& Anikeeva, P. (2015). Multifunctional fibers for simultaneous optical, electrical and chemical interrogation of neural circuits in vivo. Nature Biotechnology, 33(3), 277-284. http://dx.doi.org/10.1038/nbt.3093

Chen, J., Wise, K. D., Hetke, J. F., \& Bledsoe, S. C. (1997). A multichannel neural probe for selective chemical delivery at the cellular level. IEEE Transactions on Biomedical Engineering, 44(8), 760-769. https://doi.org/10.1109/10.605435

Chen, P.-J., Shih, C.-Y., \& Tai, Y.-C. (2006). Design, fabrication and characterization of monolithic embedded parylene microchannels in silicon substrate. Lab on a Chip, 6(6), 803. https://doi.org/10.1039/b600224b

Chen, Z.-J., Gillies, G. T., Broaddus, W. C., Prabhu, S. S., Fillmore, H., Mitchell, R. M., Corwin, F. D., \& Fatouros, P. P. (2004). A realistic brain tissue phantom for intraparenchymal infusion studies. Journal of Neurosurgery, 101(2), 314-322. https://doi.org/10.3171/jns.2004.101.2.0314

Cheung, K. C., Djupsund, K., Dan, Y., \& Lee, L. P. (2003). Implantable multichannel electrode array based on soi technology. Journal of Microelectromechanical Systems, 12(2), 179-184. https://doi.org/10.1109/JMEMS.2003.809962

De La Crompe, B., Coulon, P., \& Diester, I. (2020). Functional interrogation of neural circuits with virally transmitted optogenetic tools. Journal of Neuroscience Methods, 345, 108905. https://doi.org/10.1016/i.jneumeth.2020.108905

Deisseroth, K. (2011). Optogenetics. Nature Methods, 8(1), 26-29. https://doi.org/10.1038/nmeth.f.324

Dijkstra, M., de Boer, M. J., Berenschot, J. W., Lammerink, T. S. J., Wiegerink, R. J., \& Elwenspoek, M. (2007). A versatile surface channel concept for microfluidic applications. Journal of Micromechanics and Microengineering, 17(10), 1971-1977. https://iopscience.iop.org/article/10.1088/0960-1317/17/10/007

Drysdale, D., O'Hara, A., \& Wang, C. H. (2015). The behaviour of continuous flow xenon difluoride etching of silicon. Journal of Institute of Smart Structures and Systems (ISSS), 4(1), 70-75. https://www.isssonline.in/journal/04paper07.pdf 
Eriksson, D., Schneider, A., Thirumalai, A., Alyahyaey, M., Crompe, B. de la, Sharma, K., Ruther, P., \& Diester, I. (2021). Multichannel optogenetics combined with laminar recordings for ultra-controlled neuronal interrogation [Preprint]. In Review.

https://doi.org/10.21203/rs.3.rs-146676/v1

Fenton, G. E., Pollard, A. K., Halliday, D. M., Mason, R., Bredy, T. W., \& Stevenson, C. W. (2014). Persistent prelimbic cortex activity contributes to enhanced learned fear expression in females. Learning \& Memory, 21(2), 55-60.

https://doi.org/10.1101//m.033514.113

Groenesteijn, J., de Boer, M. J., Lötters, J. C., \& Wiegerink, R. J. (2017). A versatile technology platform for microfluidic handling systems, part II: Channel design and technology. Microfluidics and Nanofluidics, 21(7), 126.

https://doi.org/10.1007/s10404-017-1962-z

Grossman, N., Nikolic, K., Grubb, M. S., Burrone, J., Toumazou, C., \& Degenaar, P. (2011). High-frequency limit of neural stimulation with ChR2. Annual International Conference of the IEEE Engineering in Medicine and Biology Society. IEEE Engineering in Medicine and Biology Society. Annual International Conference, 2011, 4167-4170. https://doi.org/10.1109/IEMBS.2011.6091034

Han, X., \& Boyden, E. S. (2007). Multiple-color optical activation, silencing, and desynchronization of neural activity, with single-spike temporal resolution. PloS One, 2(3), e299. https://doi.org/10.1371/journal.pone.0000299

Hardung, S., Epple, R., Jäckel, Z., Eriksson, D., Uran, C., Senn, V., Gibor, L., Yizhar, O., \& Diester, I. (2017). A Functional Gradient in the Rodent Prefrontal Cortex Supports Behavioral Inhibition. Current Biology: CB, 27(4), 549-555.

https://doi.org/10.1016/..cub.2016.12.052

Herwik, S., Kisban, S., Aarts, A. A. A., Seidl, K., Girardeau, G., Benchenane, K., Zugaro, M. B., Wiener, S. I., Paul, O., Neves, H. P., \& Ruther, P. (2009). Fabrication technology for silicon-based microprobe arrays used in acute and sub-chronic neural recording. Journal of Micromechanics and Microengineering, 19(7), 074008. https://doi.org/10.1088/0960-1317/19/7/074008

Herwik, S., Paul, O., \& Ruther, P. (2011). Ultrathin Silicon Chips of Arbitrary Shape by Etching Before Grinding. Journal of Microelectromechanical Systems, 20(4), 791793. https://doi.org/10.1109/JMEMS.2011.2148159

Huffman, R. D., \& McFadin, L. S. (1972). Effects of bicuculline on central inhibition. Neuropharmacology, 11(6), 789-799. https://doi.org/10.1016/0028-3908(72)90036-6

Jackman, S. L., Beneduce, B. M., Drew, I. R., \& Regehr, W. G. (2014). Achieving HighFrequency Optical Control of Synaptic Transmission. Journal of Neuroscience, 34(22), 7704-7714. https://doi.org/10.1523/JNEUROSCl.4694-13.2014

Kim, H., Brünner, H. S., \& Carlén, M. (2020). The DMCdrive: Practical 3D-printable microdrive system for reliable chronic multi-tetrode recording and optogenetic application in freely behaving rodents. Scientific Reports, 10(1), 11838. https://doi.org/10.1038/s41598-020-68783-9

Kim, K., Vöröslakos, M., Fernández-Ruiz, A., Parizi, S. S., Ko, E., Hendrix, B., Seymour, J. P., Wise, K. D., Buzsáki, G., \& Yoon, E. (2020). HectoSTAR microLED optoelectrodes for large-scale, high-precision in invo opto-electrophysiology [Preprint]. Bioengineering. https://doi.org/10.1101/2020.10.09.334227

Kisban, S., Kenntner, J., Janssen, P., Metzen, R. v., Herwik, S., Bartsch, U., Stieglitz, T., Paul, O., \& Ruther, P. (2009). A Novel Assembly Method for Silicon-Based Neural Devices. In O. Dössel \& W. C. Schlegel (Eds.), World Congress on Medical Physics 
and Biomedical Engineering, September 7-12, 2009, Munich, Germany (pp. 107110). Springer. https://doi.org/10.1007/978-3-642-03889-1 29

Li, X., Gutierrez, D. V., Hanson, M. G., Han, J., Mark, M. D., Chiel, H., Hegemann, P., Landmesser, L. T., \& Herlitze, S. (2005). Fast noninvasive activation and inhibition of neural and network activity by vertebrate rhodopsin and green algae channelrhodopsin. Proceedings of the National Academy of Sciences of the United States of America, 102(49), 17816-17821. https://doi.org/10.1073/pnas.0509030102

Moser, D., Seidl, K., Paul, O., \& Ruther, P. (2012). Fabrication of microfluidic neural probes with in-channel electrodes. 2012 IEEE Sensors, 1-4. https://doi.org/10.1109/ICSENS.2012.6411044

Mukherjee, A., \& Caroni, P. (2018). Infralimbic cortex is required for learning alternatives to prelimbic promoted associations through reciprocal connectivity. Nature Communications, 9(1), 2727. https://doi.org/10.1038/s41467-018-05318-x

Nagel, G., Szellas, T., Huhn, W., Kateriya, S., Adeishvili, N., Berthold, P., Ollig, D., Hegemann, P., \& Bamberg, E. (2003). Channelrhodopsin-2, a directly light-gated cation-selective membrane channel. Proceedings of the National Academy of Sciences, 100(24), 13940-13945. https://doi.org/10.1073/pnas.1936192100

Neeves, K. B., Lo, C. T., Foley, C. P., Saltzman, W. M., \& Olbricht, W. L. (2006). Fabrication and characterization of microfluidic probes for convection enhanced drug delivery. Journal of Controlled Release, 111(3), 252-262. https://doi.org/10.1016/j.jconrel.2005.11.018

Park, S., Guo, Y., Jia, X., Choe, H. K., Grena, B., Kang, J., Park, J., Lu, C., Canales, A., Chen, R., Yim, Y. S., Choi, G. B., Fink, Y., \& Anikeeva, P. (2017). One-step optogenetics with multifunctional flexible polymer fibers. Nature Neuroscience, 20(4), 612-619. https://doi.org/10.1038/nn.4510

Pongrácz, A., Fekete, Z., Márton, G., Bérces, Zs., Ulbert, I., \& Fürjes, P. (2013). Deep-brain silicon multielectrodes for simultaneous in vivo neural recording and drug delivery. Sensors and Actuators B: Chemical, 189, 97-105. https://doi.org/10.1016/j.snb.2013.01.032

Retterer, S. T., Smith, K. L., Bjornsson, C. S., Neeves, K. B., Spence, A. J. H., Turner, J. N., Shain, W., \& Isaacson, M. S. (2004). Model Neural Prostheses With Integrated Microfluidics: A Potential Intervention Strategy for Controlling Reactive Cell and Tissue Responses. IEEE Transactions on Biomedical Engineering, 51(11), 20632073. https://doi.org/10.1109/TBME.2004.834288

Royer, S., Zemelman, B. V., Barbic, M., Losonczy, A., Buzsáki, G., \& Magee, J. C. (2010). Multi-array silicon probes with integrated optical fibers: Light-assisted perturbation and recording of local neural circuits in the behaving animal: Multi-array silicon probes with integrated optical fibers. European Journal of Neuroscience, 31(12), 2279-2291. https://doi.org/10.1111/j.1460-9568.2010.07250.x

Schwaerzle, M., Paul, O., \& Ruther, P. (2017). Compact silicon-based optrode with integrated laser diode chips, SU-8 waveguides and platinum electrodes for optogenetic applications. Journal of Micromechanics and Microengineering, 27(6), 065004. https://doi.org/10.1088/1361-6439/aa6ad4

Seidl, K., Spieth, S., Herwik, S., Steigert, J., Zengerle, R., Paul, O., \& Ruther, P. (2010). Inplane silicon probes for simultaneous neural recording and drug delivery. Journal of Micromechanics and Microengineering, 20(10), 105006.

https://doi.org/10.1088/0960-1317/20/10/105006 
Sharma, K., Kumar, S. D. N., Oliver Paul, \& Ruther, P. (2019). Microfluidic Neural Probes With Buried Channels Fabricated Using Continuous Flow $\mathrm{XeF}_{2}$ Etching of Silicon. Dig. Tech. Papers IEEEE MEMS Conference 2019; January 27-31, 2019, Seoul, Korea, 569-572. https://ieeexplore.ieee.org/document/8870673

Shin, H., Jeong, S., Lee, J.-H., Sun, W., Choi, N., \& Cho, I.-J. (2021). 3D high-density microelectrode array with optical stimulation and drug delivery for investigating neural circuit dynamics. Nature Communications, 12(1), 492. https://doi.org/10.1038/s41467-020-20763-3

Shin, H., Son, Y., Chae, U., Kim, J., Choi, N., Lee, H. J., Woo, J., Cho, Y., Yang, S. H., Lee, C. J., \& Cho, I.-J. (2019). Multifunctional multi-shank neural probe for investigating and modulating long-range neural circuits in vivo. Nature Communications, 10(1), 111. https://doi.org/10.1038/s41467-019-11628-5

Sim, J. Y., Haney, M. P., Park, S. I., McCall, J. G., \& Jeong, J.-W. (2017). Microfluidic neural probes: In vivo tools for advancing neuroscience. Lab on a Chip, 17(8), 1406-1435. https://doi.org/10.1039/C7LC00103G

Spieth, S., Brett, O., Seidl, K., Aarts, A. A. A., Erismis, M. A., Herwik, S., Trenkle, F., Tätzner, S., Auber, J., Daub, M., Neves, H. P., Puers, R., Paul, O., Ruther, P., \& Zengerle, R. (2011). A floating 3D silicon microprobe array for neural drug delivery compatible with electrical recording. Journal of Micromechanics and Microengineering, 21(12), 125001. https://doi.org/10.1088/0960-1317/21/12/125001

Spieth, S., Schumacher, A., Seidl, K., Hiltmann, K., Haeberle, S., McNamara, R., Dalley, J. W., Edgley, S. A., Ruther, P., \& Zengerle, R. (2009). Robust microprobe systems for simultaneous neural recording and drug delivery. In J. Vander Sloten, P. Verdonck, M. Nyssen, \& J. Haueisen (Eds.), 4th European Conference of the International Federation for Medical and Biological Engineering (Vol. 22, pp. 2426-2430). Springer Berlin Heidelberg. https://doi.org/10.1007/978-3-540-89208-3 582

Tye, K. M., \& Deisseroth, K. (2012). Optogenetic investigation of neural circuits underlying brain disease in animal models. Nature Reviews Neuroscience, 13(4), 251-266. https://doi.org/10.1038/nrn3171

Williams, K. R., Gupta, K., \& Wasilik, M. (2003). Etch rates for micromachining processingpart II. Journal of Microelectromechanical Systems, 12(6), 761-778. https://doi.org/10.1109/JMEMS.2003.820936

Wu, F., Stark, E., Ku, P.-C., Wise, K. D., Buzsáki, G., \& Yoon, E. (2015). Monolithically Integrated $\mu L E D s$ on Silicon Neural Probes for High-Resolution Optogenetic Studies in Behaving Animals. Neuron, 88(6), 1136-1148. https://doi.org/10.1016/j.neuron.2015.10.032

Zhang, F., Wang, L.-P., Brauner, M., Liewald, J. F., Kay, K., Watzke, N., Wood, P. G., Bamberg, E., Nagel, G., Gottschalk, A., \& Deisseroth, K. (2007). Multimodal fast optical interrogation of neural circuitry. Nature, 446(7136), 633-639. https://doi.org/10.1038/nature05744

Ziegler, D., Suzuki, T., \& Takeuchi, S. (2006). Fabrication of Flexible Neural Probes With Built-In Microfluidic Channels by Thermal Bonding of Parylene. Journal of Microelectromechanical Systems, 15(6), 1477-1482. https://doi.org/10.1109/JMEMS.2006.879681 